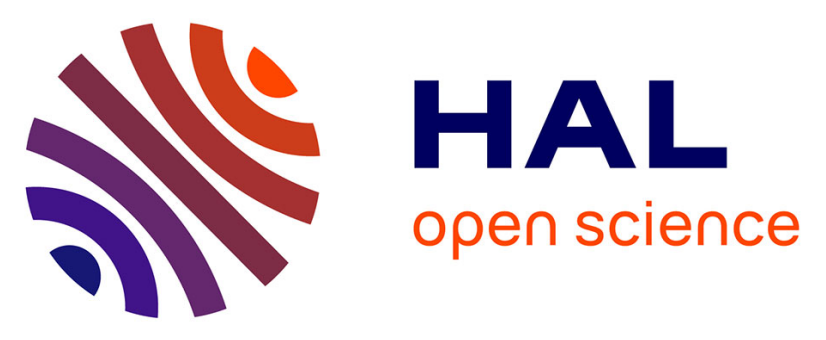

\title{
The role of osteoprotegerin in the crosstalk between vessels and bone: Its potential utility as a marker of cardiometabolic diseases
}

Luc Rochette, Alexandre Meloux, Eve Rigal, Marianne Zeller, Yves Cottin, Catherine Vergely

\section{To cite this version:}

Luc Rochette, Alexandre Meloux, Eve Rigal, Marianne Zeller, Yves Cottin, et al.. The role of osteoprotegerin in the crosstalk between vessels and bone: Its potential utility as a marker of cardiometabolic diseases. Pharmacology and Therapeutics, 2018, 182, pp.115-132. 10.1016/j.pharmthera.2017.08.015 . hal-03431587

\section{HAL Id: hal-03431587 \\ https://u-bourgogne.hal.science/hal-03431587}

Submitted on 16 Nov 2021

HAL is a multi-disciplinary open access archive for the deposit and dissemination of scientific research documents, whether they are published or not. The documents may come from teaching and research institutions in France or abroad, or from public or private research centers.
L'archive ouverte pluridisciplinaire HAL, est destinée au dépôt et à la diffusion de documents scientifiques de niveau recherche, publiés ou non, émanant des établissements d'enseignement et de recherche français ou étrangers, des laboratoires publics ou privés. 


\title{
The role of osteoprotegerin in the crosstalk between vessels and bone: its potential utility as a marker of cardiometabolic diseases
}

\author{
Luc Rochette ${ }^{1}$, Alexandre Meloux ${ }^{1}$, Eve Rigal ${ }^{1}$, Marianne Zeller ${ }^{1}$, Yves Cottin $^{1,2}$, Catherine Vergely ${ }^{1}$ \\ ${ }^{1}$ Equipe d'Accueil (EA 7460): Physiopathologie et Epidémiologie Cérébro-Cardiovasculaires (PEC2) \\ Université de Bourgogne - Franche Comté ; Faculté des Sciences de Santé ; 7 Bd Jeanne d’Arc, 21000 \\ Dijon - France \\ ${ }^{2}$ Service de Cardiologie - CHU-Dijon - France. \\ E-mail address: luc.rochette@u-bourgogne.fr
}

\section{ABSTRACT}

Among the numerous molecules that are being studied for their potential utility as biomarkers of cardiovascular diseases, much interest has been shown in the superfamily of tumor necrosis factor (TNF) receptors. Members of this family include osteoprotegerin (OPG) and its ligands, which are receptor activators of nuclear factor $\mathrm{kB}$ ligand (RANKL) and TNF-related apoptosis-inducing ligand (TRAIL). These signals may be expressed and regulated, and their functions could be involved in several physiological and pathological processes. The relationship between bone regulatory proteins and vascular biology has attracted attention, and it has been suggested that OPG may mediate vascular calcification and cardiometabolic diseases. OPG is steadily released from vascular endothelial cells in response to inflammatory stimuli, suggesting that it plays a modulatory role in vascular injury, inflammation, and atherosclerosis. Vascular calcification, a hallmark of atherosclerosis, is similar to bone remodeling. It is an actively regulated mechanism that includes both inductive and inhibitory processes. There is a temporal link between the development of osteoporosis and vascular calcification, which is particularly marked in post-menopausal women and the elderly. The precise nature of the link between bone metabolism, vascular calcification and cardiovascular disease is largely unknown but increasing evidence suggests that the triad of RANK/RANKL/OPG may be important in the initiation of various diseases. An increased release of OPG is associated with increased cardiovascular risk and it is suggested that increased OPG levels resulting from vascular damage correspond to a protective mechanism. Circulating OPG levels could be used as independent biomarkers of cardiovascular disease in patients with acute or chronic cardiometabolic disease and thus an improved prognosis. 


\section{Contents}

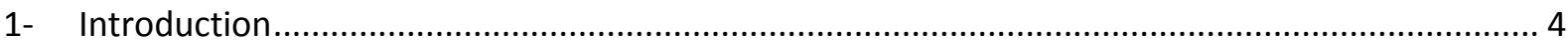

2- Overview of the regulation of bone mineralization ................................................................. 5

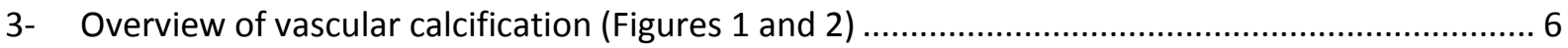

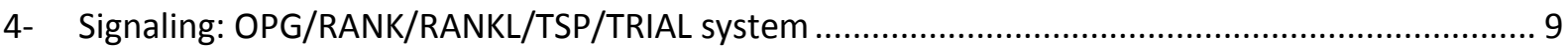

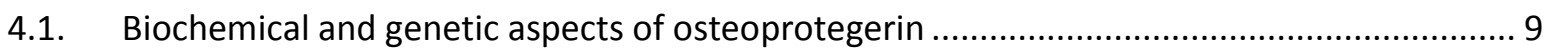

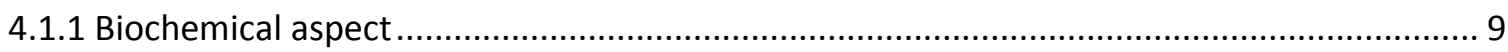

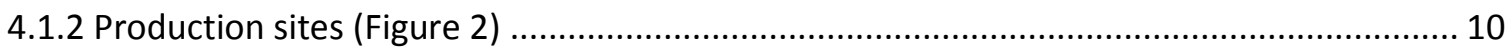

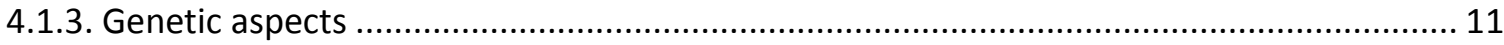

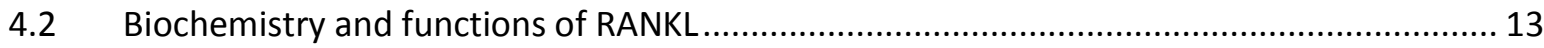

4.3 Biochemical crosstalk between endothelial cells and osteocytes ..................................... 14

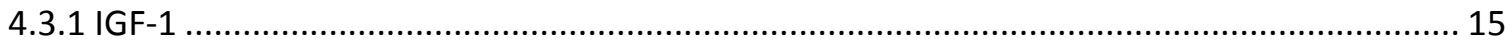

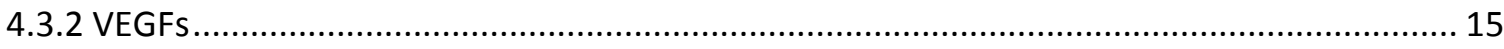

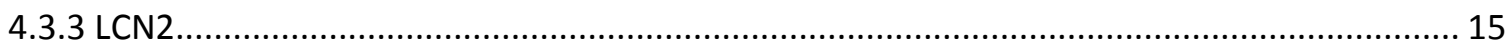

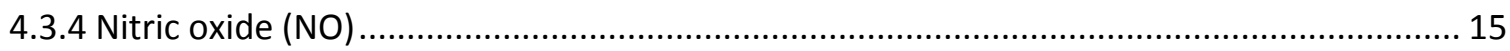

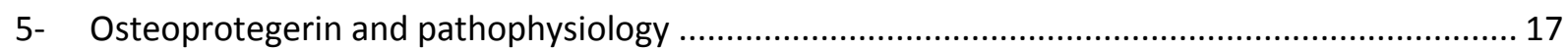

5.1. Approach via genetic manipulations in animal and human genetic data........................... 17

5.2 OPG: an inhibitory factor of osteoclastogenesis ......................................................... 18

6- Osteoprotegerin in cardio-metabolic disorders ........................................................................ 20

6.1 Implication of the OPG/RANK/RANKL in heart diseases: heart failure and atrial fibrillation 20

6.2 OPG plays a significant role in the physiology of endothelial cells ..................................... 21

7- Positive relationship between circulating osteoprotegerin, vascular damage, and metabolic

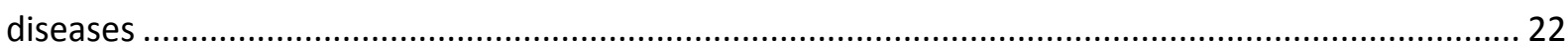

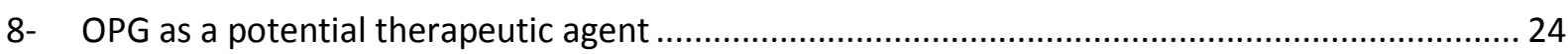

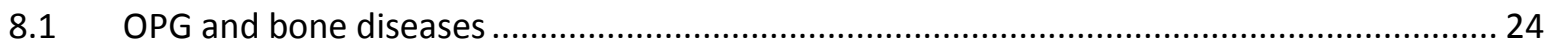

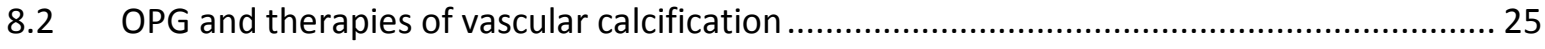

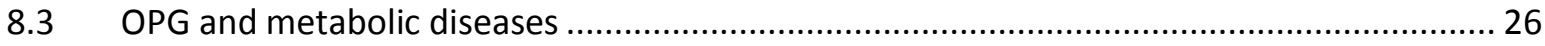

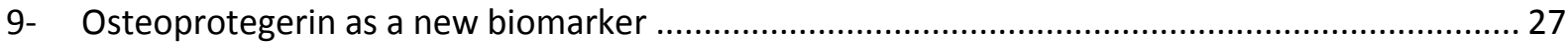

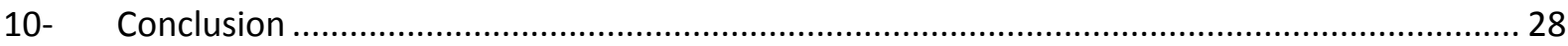

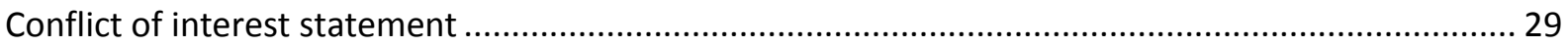

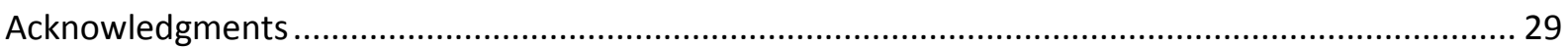

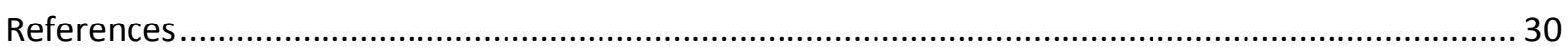

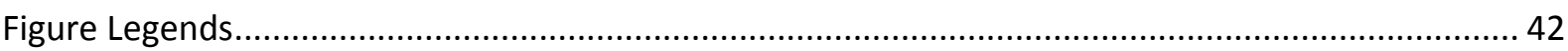




\section{Abbreviations}

aa, amino acid; ADMA, asymmetric dimethylarginine; $A F$, atrial fibrillation; ALP, alkaline phosphatase; $\mathrm{BMI}$, body mass index; BMP, bone morphogenic protein Cys, cysteine; CAD, Coronary artery disease; CKD, Chronic kidney disease; CRD, cysteine rich domain; CVD, cardiovascular disease; DDHs, death domain homologous regions; DR, death receptors; EC, endothelial cell; ECD, extracellular domain; ECFC, endothelial colony-forming cell; EPC, endothelial progenitor cell; EVs, extracellular vesicles; ER, estrogen receptor ; FGF-23, Fibroblast growth factor-23; GAG, glycosaminoglycan; GDF-15, growth differentiation factor-15; GLA, gamma-carboxyglutamic acid; GPR-48, G-protein-coupled receptor 48 hCRP, high sensitivity C-reactive protein HIF, hypoxia-inducible factor; HOMA, homeostatic model assessment; HS, heparan sulfate; Hs-CRP, high sensitivity C-reactive protein; HSPGs, heparan sulfate proteoglycans; HUVEC, Human umbilical cord vein endothelial cells; ICAM, intercellular adhesion molecule IGF, insulin-like growth factor: IGFR, IGF receptor; IL-1, Interleukin 1; IRF, interferonregulatory factor; kDa, Kilodalton; L-Arg,L-arginine LCN2, lipocalin -2; LDLR, low-density lipoprotein receptor; LGR, leucine-rich repeats containing G-protein-coupled receptors; LRP, lipoprotein-related receptor; MAPK, mitogen-activated protein kinase; MCP, monocyte chemotactic protein-; miRNA, microRNA; MetS, metabolic syndrome; MMP, matrix metalloprotease; MSC, mesenchymal stem cell; MVP, mitral valve prolapse; NADP, nicotinamide adénine dinucléotide phosphate; $\mathrm{Nf}-\mathrm{KB}$, nuclear factor KB ;NO, nitric oxide; NOS, NO synthetase; NOX, NADPH oxidase; Nrf2, nuclear factor-E2-related factor 2;NT-proBNP, N-terminal Pro-Brain Natriuretic Peptide; OCIF, Osteoclastogenesis inhibitory factor; OP, osteoporosis; OPG, osteoprotegerin; PAH, pulmonary arterial hypertension; PG, proteoglycan; PI3-kinase, phosphatidyl inositol 3-kinase; PTH, parathyroid hormone; PWV, pulse wave velocity; RA, rheumatoid arthritis; RANK, Receptor activator of nuclear factor $\mathrm{K} B$; RANKL, Receptor activator of nuclear factor $\mathrm{k} B$ ligand; ROS, reactive oxygen species; RNS, reactive nitrogen species; RSPO, roof-plate-specific spondin; RUNX2, runt-related transcription factor-2; SLE, systemic lupus erythematosus; ST2, suppression of tumorigenicity 2; TGF, transforming growth factor; TNF, tumor necrosis factor; TNFR,; tumor necrosis factor receptor TNFRS, tumor necrosis factor receptor superfamily TRAIL, tumor necrosis factor-related apoptosis-inducing ligand; TRAF, TNFR-associated factor TSP-1, thrombospondin-1; VCAM, vascular adhesion molecule; VDR, vitamin D receptor; VEGF, vascular endothelial growth factor; VSMC, vascular smooth muscle cells; vWF, von Willebrand factor; WPB, Weibel-Palade bodies. 


\section{1- Introduction}

Cardiovascular diseases (CVD) remain a major cause of premature death and chronic disability for all regions of the world. Ischemic heart disease (IHD) and stroke account for the majority of health lost to CVD. Moreover, current predictions estimate that by the year 2020 cardio-metabolic diseases, notably atherosclerosis and diabetes, will become the leading global cause of total disease burden. Diabetes mellitus affects 1 in 10 US adults, with 90\% to 95\% of cases being type 2 diabetes mellitus (Roth, et al., 2015; Writing Group, et al., 2016).

Primary and secondary preventive actions are required to limit or stop the development of CVD. The identification of markers able to detect the early stages of such diseases is essential so that action can be taken to attenuate the deteriorating clinical situation.

Among the numerous molecules being studied for their potential utility as CVD biomarkers, much attention is being paid to the superfamily of tumor necrosis factor (TNF) receptors. Members of this family include osteoprotegerin (OPG), and its ligands, which are receptor activators of nuclear factor kappa-B ligand (RANKL) and TNF-related apoptosis-inducing ligand (TRAIL). Classically, the OPG/RANK/RANKL network is involved in bone remodeling and regulates the differentiation and activation of osteoclasts and hence the critical balance between bone formation and bone resorption (Theoleyre, et al., 2004; Walsh \& Choi, 2014).

Recently, a relationship between bone regulatory proteins and vascular biology has attracted attention, and it has been suggested that OPG may mediate vascular calcification. Vascular calcification has a variety of forms, including intimal calcification and medial calcification, but can also be found in the valves of the heart. Vascular calcification is a hallmark of atherosclerosis and is associated with diabetes, cardiovascular diseases and kidney diseases, especially chronic kidney disease (CKD) (Cianciolo, et al., 2014; Nicoll, Zhao, Ibrahimi, Olivecrona, \& Henein, 2016).

Patients with vascular calcification are at higher risk for adverse cardiovascular events (Nakahara, et al., 2017). Vascular calcification, like bone remodeling, is an actively regulated process that includes both inductive and inhibitory processes. The precise nature of the link between vascular calcification and cardiovascular disease is largely unknown but growing evidence suggests that the triad of RANK/RANKL/OPG may be important in vascular calcification (Harper, et al., 2016).

The objective of this review article is 1 ) to provide an overview of the main physiological and pathophysiological aspects of OPG and 2) to encourage diagnostic value of serum OPG levels for clinical use and assess its potential utility as a marker of cardio-metabolism. In the first part of the following section, we summarize the main characteristics of bone mineralization and vascular calcification. 


\section{2- Overview of the regulation of bone mineralization}

Bone is a dynamic organ, once formed it is continually broken-down and reformed by the action of osteoblasts, which mediate bone formation, and osteoclasts, which mediate bone resorption. Coupling between bone formation and bone resorption (remodeling) refers to a process within multicellular units.

The blood vessels in bone are necessary for nearly all skeletal functions, including development, homeostasis, and repair. A dense vascular network delivers oxygen and nutrients (minerals such as calcium) to all 206 bones in the human body (Tomlinson \& Silva, 2013). Osteoclasts are the main mineral-resorbing cells in the body (Tomlinson \& Silva, 2013) and require coordinated co-stimulation by several signaling pathways to initiate and regulate their cellular differentiation. They are formed from fusing mononuclear precursor cells of the myeloid lineage and differentiate in response to cytokines, including macrophage colony-stimulating factor (M-CSF) RANK and RANKL (Iwai, et al., 2007). RANK is a type I membrane protein expressed on the surface of osteoclasts (Sims \& Martin, 2014, 2015).

Most adult skeletal diseases such as osteoporosis (OP) result from the disruption of bone homeostasis. OP is characterized by decreased bone mineral density (BMD) and poor bone quality, with a deterioration in skeletal microarchitecture and a predisposition to fracture. The treatment of osteoporosis is based on two types of drugs to increase BMD: antiresorptive and anabolic agents. Antiresorptive drugs inhibit osteoclasts. OP and CVD were considered independently related to aging. Nonetheless, increasing data in recent years suggest a close relationship between OP and atherosclerosis, corresponding to crosstalk between vessels and bones (Cianciolo, et al., 2014; Nakahara, et al., 2017; Nicoll, et al., 2016).

Age-related OP in patients has a multifactorial etiology. Decreased bone formation, caused by agerelated changes in levels of reactive oxygen species (ROS), insulin-like growth factor-1 (GF-1), and parathyroid hormone (PTH), plays a predominant role in the pathogenesis of age-related OP. The frequent coexistence of OP and vascular calcification has led to the hypothesis of common pathways. A growing body of evidence suggests that secretory proteins belonging to the TNF receptor superfamily, which were initially associated with bone mineral density regulation, play an important role as mediators of inflammation, vascular remodeling and vascular calcification (Vassalle \& Mazzone, 2016). The discovery and characterization of the cytokine receptor-cytokine-decoy receptor triad formed by receptor activator of RANKL-RANK-OPG have led to important advances in our understanding of the biology of bone homeostasis and of the relationship between immunity and various cardiovascular diseases (Walsh \& Choi, 2014). Several molecules involved in the immune system have also been shown to have essential functions in bone turnover (Weitzmann \& Ofotokun, 2016) and vessels (Pober \& Tellides, 2012). Various proteins are implicated not only in the balance 
between bone formation and resorption but also in vascular calcification. The mechanisms that regulate vascular calcification are complex: inflammatory and metabolic factors all affect these processes. OPG, an amino-acid signal peptide identified in 1997 (Simonet, et al., 1997), appears to play a very important role in the crosstalk between bones, vessels and the heart (Harper, et al., 2016). The molecular mechanisms involved in the regulation of vascular calcification are still not fully delineated and there are conflicting reports concerning the role of OPG in vascular and heart function in normal and pathological conditions (Sage, Tintut, \& Demer, 2010).

\section{3- Overview of vascular calcification (Figures 1 and 2)}

Vascular calcification is a risk factor of cardiovascular and all-cause mortality in diseased patients. However, the molecular basis of vessel mineralization remains unclear. Ectopic vessel mineralization can occur in the tunica intima or in the tunica media of the vessel and is associated with atherosclerosis resulting in atherosclerotic plaques. Calcification can also occur in the media and is present in the elderly and in patients with OP, CKD, or diabetes mellitus. One major hypothesis of vascular calcification is that it is a consequence of active bone formation in situ by osteoblast-type cells. VSMCs are major precursors contributing to osteochondrogenesis and calcification in atherosclerosis. The vascular wall contains osteoclast precursors in the form of monocytes, and a trans-differentiation process gives VSMCs an osteogenic phenotype (Persy \& D'Haese, 2009). Vascular calcification is an active cell-mediated process and like osteogenesis it involves the expression of bone-related proteins, such as alkaline phosphatase (ALP) and Runt-related transcription factor-2 (Runx2), which are initiators of bone mineralization and SMC differentiation. The expression of ALP has been demonstrated in calcified atherosclerotic lesions (Shioi, et al., 2002). SMC-specific Runx2 plays critical roles in both osteoblastic differentiation and the maturation of chondrocytes during atherosclerosis-induced vascular calcification (Lin, et al., 2016). Furthermore, the Wnt/b-catenin axis regulates Runx2 expression thus controlling osteoblast differentiation. In osteoblasts, as reported above, the Wnt/b-catenin pathway controls the expression of OPG and RANKL, thus contributing to the regulation of osteoclasts (Haxaire, Hay, \& Geoffroy, 2016). VSMCs synthetize much greater amounts of OPG than do ECs and play a significant role in the progression of vascular calcification as do adventitial myofibroblasts and pericyte-like calcifying vascular cells (Johnson, Leopold, \& Loscalzo, 2006).

Calcified lesions contain many bone matrix proteins, such as collagen type I, osteocalcin, osteonectin, osteopontin, Gla-protein, and bone morphogenic protein 2 (BMP-2) (Giachelli, et al., 1993). The correlation between increased aortic ALP activity and the aortic calcification area in OPG-/- mice 
suggests that OPG plays an anti-calcification role through the downregulation of ALP activity (Orita, et al., 2007). The roles of a variety of bone-related proteins, including ALP, BMP-2 and Gla, are complex and interactive.

Concerning the clinical domain, numerous studies have reported higher serum OPG levels in association with poorer cardiovascular outcomes in the contexts of coronary diseases (CAD), abdominal aortic aneurysms, and cardiovascular mortality. The studies demonstrated that an increase in the serum OPG level is a predictor of cardiovascular mortality in patients with stable CAD (Jono, et al., 2010; Venuraju, Yerramasu, Corder, \& Lahiri, 2010). In a 10-year follow-up survey, serum OPG levels were found to be an independent risk factor for the progression of atherosclerosis as well as the incidence of and mortality from cardiovascular disease (Kiechl, et al., 2006). Human studies have demonstrated a favorable role of TRAIL in cardiovascular diseases such as heart disease, coronary atherosclerosis and coronary disorders (Deftereos, et al., 2012; Niessner, et al., 2009). OPG levels are associated with carotid intima-media thickness in CAD patients. OPG predicts early carotid atherosclerosis in patients with CAD (Montecucco, Steffens, \& Mach, 2007; Morisawa, et al., 2015). In CKD patients, vascular calcification is frequent and the prognosis is similar to that for cardiovascular mortality. In CKD patients, it is suggested that increased OPG levels in kidney disease patients is the result of impaired renal clearance. In dialysis patients, vascular calcification is always present (Jono, Shioi, Ikari, \& Nishizawa, 2006). OPG, RANKL and TRAIL concentrations were measured in hemodialyzed CKD patients. Plasma OPG concentrations were higher in CKD patients than in controls whereas total soluble RANKL was lower. The OPG/RANKL ratio was therefore higher in these patients. In contrast, soluble TRAIL concentrations did not differ between the groups. Recent studies have confirmed the role of OPG as a predictor of mortality in CKD (Alderson, et al., 2016; Kuzniewski, et al., 2016).

Different factors significantly correlate with serum OPG levels in patients with CKD. Increased serum levels of OPG in dialysis and predialysis patients with chronic renal failure compared with renal transplant patients and controls were studied. In the patient groups receiving two dialysis treatments, the levels of OPG were even higher, signifying major vascular injury (Demir, et al., 2016). Increased levels of OPG in dialysis patients may be related to uremic stimulation and the dialysis procedure. Recent studies demonstrated the effects of PTH and vitamin D acting in synergy with fibroblast growth factor 23 (FGF-23) on the evolution of CKD.

Elevated levels of FGF-23 are clinically associated with endothelial dysfunction and arterial stiffness in CKD patients. FGF-23 levels are associated with cardiovascular mortality in patients with CKD (Singh, et al., 2016). In patients with CKD, phosphate is an important stimulus among the various factors associated with vascular calcification. In the control of phosphate homeostasis, FGF-23 has been identified as an endogenous regulator that induces urinary phosphate wasting. FGF-23, 
secreted from osteocytes in response to phosphate load, inhibits the expression of the renal $\mathrm{Na} / \mathrm{P}(\mathrm{i})$ cotransporter system (Baum, Schiavi, Dwarakanath, \& Quigley, 2005) (Figure 1). In CKD patients, it has recently been demonstrated 1) that FGF-23 mediated inhibition of osteogenic differentiation of VSMC and induction of OPG gene expression, 2) that FGF-23 induced OPG mRNA expression, at least in part, through the protein klotho, and fibroblast growth factor receptors (FGFR-1) (Nakahara, et al., 2016). Klotho is an anti-ageing protein and its expression levels in blood decline during ageing. Klotho regulates phosphate homeostasis and signaling (Wnt and insulin) and interacts with FGFR-1 to form a high-affinity receptor for FGF-23. Interestingly, Klotho was found to protect SMCs against induced oxidative stress and perhaps through this property, Klotho ameliorates vascular endothelial dysfunction and delays vascular calcification. The vascular phenotype of klotho deficiency is very similar to both human ageing and that observed in CKD (Mencke, Hillebrands, \& consortium, 2017). Concerning the "protective effects" of OPG on ECs, the role of EPCs is suggested. These cells are recruited from bone marrow and are incorporated into sites of active vascularization. In the group of EPCS, only endothelial colony-forming cells (ECFCS) possess the characteristics of endothelial progenitors. OPG enhances the proangiogenic properties of ECFCs; this action has been demonstrated in vitro and also in vivo during vasculogenesis. OPG may interact with ECFCs by binding to heparan sulfate proteoglycans (HSPGs)/syndecan-1. As a consequence, HSPGs may regulate OPG bioavailability (Benslimane-Ahmim, et al., 2013). OPG is able to activate specific signaling pathways, especially protein kinase $C$ and phosphatidylinositol3-kinase/Akt via syndecan-1, thus supporting the role of syndecans in cell adhesion and migration (Mosheimer, et al., 2005). Interestingly, serum levels of proteoglycan syndecans are increased in common inflammatory disorders such as RA or systemic lupus erythematosus (SLE) (Kim, Kim, Baek, Kim, \& Cho, 2015).

An association between elevated serum OPG levels and enhanced EC activation has been demonstrated in patients with RA, and OPG concentrations are associated with the prevalence of cardiovascular disease in patients with RA (Lopez-Mejias, et al., 2015). Several studies support the implication of genetic factors in the development of cardiovascular disease in RA. Cardiovascular disease in RA is the result of a complex interaction between classical cardiovascular risk factors, genetic parameters and inflammation (Lopez-Mejias, et al., 2016). An association of these genetic variants with cardiovascular events was observed in patients with RA who carried the HLADRB1*0404 allele. Endothelial dysfunction has been observed in RA patients. Interactions between NO synthase gene polymorphisms and HLA-DRB1 alleles for the risk of developing cardiovascular events have been assessed (Gonzalez-Gay, et al., 2009). In patients, levels of OPG and asymmetric dimethylarginine (ADMA), an endogenous and competitive inhibitor of NO synthases and a biomarker of EC activation, are useful for the prediction of CV diseases (Rochette, et al., 2013). 
Recent studies showed that NO inhibited VSMC calcification and osteoblastic differentiation of VSMCs (Kanno, Into, Lowenstein, \& Matsushita, 2008; Veeriah, et al., 2016).

\section{4- Signaling: OPG/RANK/RANKL/TSP/TRIAL system}

\subsection{Biochemical and genetic aspects of osteoprotegerin}

\subsubsection{Biochemical aspect}

OPG is a cytokine of the TNF receptor superfamily. It was named OPG because of its protective effects in bone (Latin: "os" bone and "protegere" to protect). OPG is also known as osteoclastogenesis inhibitory factor (OCIF) or TNF receptor superfamily member $11 \mathrm{~b}$ : (TNFRS11B). Biochemically, OPG is a basic secretory glycoprotein composed of 401 amino acids (aa) with a monomeric weight of 60 kiloDaltons $(\mathrm{kDa})$. It is then assembled at the cys-400 residue in the heparin binding domain to form a 120 kDa disulfide-linked dimer for secretion (Schneeweis, Willard, \& Milla, 2005).

OPG levels are gender-specific, i.e. women have higher OPG levels than men. Furthermore, OPG is strongly associated with age (Mogelvang, et al., 2013). Recently, it has been demonstrated that OPG levels were associated with blood group phenotypes and higher in non-zero individuals. The $A$ and $A B$ blood group carriers presented the highest OPG values in patients with peripheral artery disease and in controls (Nagy, et al., 2016).

OPG is encoded by the TNFRSF11B gene. The human OPG gene is a single-copy gene clustered on chromosome 8 (8q24). Two death domain homologous regions (DDHs) present in tandem in OPG are encoded separately by exons 4 and 5 . The gene is up-regulated by calcium and hormones: estrogens and glucocorticoids (Morinaga, Nakagawa, Yasuda, Tsuda, \& Higashio, 1998). OPG contains seven structural domains, which influence its biological activities in specific ways (Baud'huin, et al., 2013). The first one (domains 1-4) is a cysteine-rich domain essential for the inhibition of osteoclastogenesis and the dimerization of OPG via Cys400. The second domain (domains 5 and 6) comprises two death domains that mediate death domain homologous regions. The third one, corresponding to domain 7 , contains a heparin-binding site located in the C-terminal. Prior to secretion of both the monomeric and dimeric forms of OPG, the 21 aa signal peptide is cleaved from the N-terminal rendering a 380 aa mature OPG protein (Yamaguchi, et al., 1998).

Consequently, circulating measurable OPG exists either as a free monomer of $60 \mathrm{kD}$ and a disulfide bond-linked homodimer form of $120 \mathrm{kD}$, or as OPG bound to its ligands, RANKL, and TRAIL. RANKL binds as a homotrimer to RANK on target cells, which triggers activation of nuclear factor KB (NF-KB), resulting in its translocation to the nucleus (Kuroda \& Matsuo, 2012). TRAIL functions as a 
homotrimer and mediates its biological activity through TRAIL receptors. TRAIL is a type II transmembrane protein that is expressed by numerous cell types including vascular cells, immune cells and adipocytes. TRAIL can bind up to five distinct receptors to activate complex signaling pathways (Forde, et al., 2016). In spite of its name (apoptosis-inducing), it has been shown to have both pro-and anti-apoptotic activities (Secchiero, et al., 2008).

OPG binds RANKL through its N-terminal cysteine-rich domains (CRD) and CRDs are sufficient to inhibit RANKL. An interesting feature of OPG is that it exists naturally, as we previously reported, in both the monomer and dimer form. Studies have investigated the interactions between OPG and glycosaminoglycans (GAGs). GAG chains are a class of long linear polysaccharides that are covalently attached to multiple core proteins to form proteoglycans (PGs), such as heparan sulfate (HS). OPG is characterized by a high-affinity HS binding protein. The pre-incubation of OPG with heparin inhibits OPG binding to the RANK-RANKL complex in a dose-dependent manner. GAGs from different structures/origins (heparan sulfate, dermatan sulfate, and chondroitin sulfate) exert similar activities on OPG binding (M. Li, Yang, \& Xu, 2016; Theoleyre, et al., 2006). In summary, HS regulates the function of OPG by inducing OPG dimerization, altering OPG conformation, and by forming a ternary complex with OPG and RANKL.

\subsubsection{Production sites (Figure 2)}

OPG is highly expressed in various tissues such as the heart, lung, kidney, liver, bone marrow and immune system (dendritic cells). OPG is expressed in vivo by endothelial cells (ECs), vascular smooth muscle cells (VSMCs) and osteoblasts. OPG has been detected by immunohistochemistry in aortic and coronary atherosclerotic plaques, within or in the proximity of VSMCs. It is detected at very low levels in the brain, placenta, and skeletal muscle (Schoppet, et al., 2007; Simonet, et al., 1997). Patients with carotid calcification in carotid artery disease had an increased serum OPG concentration. It could thus be hypothesized that OPG plays an important role in arteriosclerosisrelated calcification.

OPG is released under basal conditions by ECs upon stimulation with inflammatory cytokines, hormones and various circulating compounds. TNF- $\alpha$ and IL-1 $\beta$ were found to increase OPG levels. Within ECs, OPG is associated with von Willebrand factor (VWF) within secretory granules called Weibel-Palade bodies (WPBs). Upon stimulation with TNF- $\alpha$ or interleukin-1 $\beta$ (IL-1 $\beta$ ) in vitro, the OPG-von Willebrand factor complex is secreted into the surrounding medium. This complex is present in human serum, indicating that EC activation by cytokines is one of the possible sources of circulating OPG in patients with diseases associated with inflammatory processes, such as atherosclerosis or diabetes (Zannettino, et al., 2005). The multimeric size of vWF can be controlled by the glycoprotein, thrombospondin-1 (TSP-1). The identification of several classes of roof-plate- 
specific spondin (RSPO: R-spondins) receptors indicates that this family of proteins can affect several signaling cascades. VWF reductase activity was present in the $\left(\mathrm{Ca}^{++}\right)$-binding repeats and $\mathrm{C}$-terminal sequence of TSP-1 (Pimanda, et al., 2002). TSP-1 is an important extracellular matrix component that influences the function of VSMCs, ECs, fibroblasts and inflammatory cells with important implications for cardiovascular diseases. TSP1, via its necessary receptor CD47, inhibits nitric oxide (NO)stimulated soluble guanylate cyclase activation in VSMCs (Bauer, et al., 2010; Krishna \& Golledge, 2013). The OPG/TSP-1 tandem is implicated in the failure of pancreatic $\beta$-cells, thus initiating the pathogenesis of type 2 diabetes. It has been demonstrated that TSP-1 plays an important role in $\beta$ cell survival during lipotoxic stress in rat, mouse and human models. TSP-1 acts from within the endoplasmic reticulum to activate nuclear factor-E2-related factor 2 (Nrf2), inducing a protective antioxidant defense response against lipotoxic stress (Cunha, et al., 2016). Nrf2 signaling modulates many physiological and pathophysiological processes, such as lipid homeostasis, atherosclerosis, diabetes, redox regulation and inflammation (Mimura \& Itoh, 2015; Rochette, et al., 2013; Rochette, Zeller, Cottin, \& Vergely, 2014). Activation of the p53 pathway down-regulates OPG expression and the release by vascular ECs (Secchiero, et al., 2008).

In vitro, bone marrow mesenchymal stem cell (MSC)-derived vascular SMC released higher levels of OPG into the culture supernatant. OPG acts as an autocrine/paracrine growth factor for vascular SMC; its effects might contribute to the progression of calcification in the vessel during atherosclerosis (Corallini, Gonelli, D'Aurizio, di lasio, \& Vaccarezza, 2009).

Important observations are that vascular calcification is often greater in patients with osteoporosis, independently of age, and that a deficiency in OPG leads to calcification (Bucay, et al., 1998; Sage, et al., 2010). These results demonstrate a distinct mechanism of bone and vascular calcification and a tissue-specific function of OPG in atherosclerosis progression (Schweighofer, et al., 2016).

An association between OPG and aneurysm development in human abdominal aortic aneurysm (AAA) has been demonstrated. Immunodetection of OPG in abdominal aorta aneurysm biopsies localized the protein primarily within the fragmented arterial media, where it was associated with an infiltration of inflammatory cells: monocytes/macrophages (Moran, et al., 2005). The concentration of OPG in the aortic wall is positively related to established markers of AAA severity and pathogenesis (Koole, et al., 2012).

\subsubsection{Genetic aspects}

Few studies have focused on the direct association between OPG genetic polymorphisms and various pathologies. OPG has traditionally been implicated in bone remodeling and OP. There is now emerging evidence that OPG polymorphisms participate in the pathogenesis of cancers, atherosclerosis and cardiovascular diseases. 
A number of polymorphisms of the OPG gene in the promoter region, in exons $1-5$, and in introns 14, including polymorphisms $149 \mathrm{~T} \rightarrow \mathrm{C}, 163 \mathrm{~A} \rightarrow \mathrm{G}, 209 \mathrm{G} \rightarrow \mathrm{A}, 245 \mathrm{~T} \rightarrow \mathrm{G}, 950 \mathrm{~T} \rightarrow \mathrm{C}$ (all promoter), 1181 $\mathrm{G} \rightarrow \mathrm{C}$ (exon 1), and $6890 \mathrm{~A} \rightarrow \mathrm{C}$ (intron 4) have been described in different diseases. Each polymorphism has been evaluated in specific diseases. For example, the frequency of the OPG gene single nucleotide A163G polymorphism has been studied in diabetic patients with microvascular and macrovascular complications. It has been reported that changes in serum OPG levels are influenced by genetic polymorphisms, including 950T/C at the rs2073617 locus and, $1181 \mathrm{G} / \mathrm{C}$ at the rs2073618 locus (Vidal, Formosa, \& Xuereb-Anastasi, 2011). The $1181 \mathrm{G} \rightarrow C$ polymorphism is located in the upstream region of exon 1, which encodes the signal peptide of the OPG protein and results in a lysine to asparagine substitution.

Polymorphism in the promoter region of the human OPG gene may contribute to the genetic regulation of bone mass (Hofbauer \& Schoppet, 2002). Polymorphism in the OPG gene correlates with mineral density of the lumbar vertebrae in postmenopausal women (Zhao, et al., 2005). One consequence of specific mutations may be diseases which manifest as bone deformation and abnormal ossification (Arko, Prezelj, Kocijancic, Komel, \& Marc, 2005).

Numerous studies have been designed to assess the association between gene polymorphisms of the OPG gene, the serum OPG level, and the development of atherosclerosis in the presence or absence of rheumatoid arthritis (RA). In this field, recent results suggest that a polymorphism of the TNFRSF11B gene is associated with the presence of coronary atherosclerosis in patients with RA (Chung, et al., 2015; Genre, et al., 2014). A number of polymorphisms of the OPG gene (including polymorphism genotypes $950 \mathrm{TC} / 1181 \mathrm{GC}$ and $950 \mathrm{CC} / 1181 \mathrm{CC}$ ) have been found in patients with coronary artery disease. Serum OPG levels correlated with the presence of a $\mathrm{C}$ allele at position 950. Genotypes 950 TC/1181 GC and 950 CC/1181 CC were overrepresented in men with CAD (Soufi, et al., 2004). In a Swedish cohort, the homozygous polymorphism 950 CC was found to be concurrently associated with increased intima-media thickness in the common carotid artery and reduced maximal post-ischemic forearm blood flow, both of which are early structural and functional indicators of atherosclerosis (Brandstrom, et al., 2002).

Concerning metabolic diseases such as metabolic syndrome and diabetes, the results of recent studies suggest that OPG gene polymorphism may play an important role in the initiation and outcome of these diseases. The frequency of the OPG gene single nucleotide A163G polymorphism and its association with diabetic microvascular and macrovascular complications has been studied. The mechanisms underlying the regulation of OPG levels, OPG polymorphism and metabolic diseases are currently not fully elucidated. Statistical analysis showed no significant difference in the distribution of the OPG A163G polymorphism in diabetic patients and control groups (Guo, Hu, Zhang, Wang, \& Liu, 2013; Perez de Ciriza, et al., 2014; Soysal-Atile, et al., 2015). 


\subsection{Biochemistry and functions of RANKL}

RANKL is mainly expressed on infiltrating T cells and activated ECs. RANK is expressed on monocytic osteoclast precursors and dendritic cells. RANKL plays an important role in immune responses. RANKL and RANK are undetected in non-diseased human vessels, while OPG is expressed in normal arteries (Mogelvang, et al., 2013; Van Campenhout \& Golledge, 2009).

RANKL-RANK complexes are likely to be internalized via rafts and then degraded in lysosomes. Human RANK consists of 616 aa (Figure 3). These aa are divided into a C-terminal cytoplasmic domain of 383 aa, an N-terminal extracellular domain of 184 aa, a signal peptide of 28 aa and a transmembrane domain of 21 aa, which contains four cysteine and two N-glycosylation sites.

Human and murine RANKL proteins share $83-87 \%$ homology, with the largest murine transmembrane isoform comprising 316 aa. Sequence analysis of the murine RANKL gene (316 aa) compared with the human RANKL gene (317 aa) showed two potential N-glycosylation sites in the extracellular domain at amino acid fragment positions 197 and 263 (Wright, McCarthy, Middleton, \& Marshall, 2009). RANKL contributes to vascular calcification by regulating bone morphogenetic protein-2 and matrix Gla (gamma-carboxyglutamic acid) protein expression (Schurgers, Cranenburg, $\&$ Vermeer, 2008). These actions were counteracted by estrogen in a receptor-dependent manner (Osako, et al., 2010).

RANKL is a transmembrane protein, but a soluble form (soluble RANKL: SRANKL) also circulates in the blood. SRANKL is thought to be produced by cleavage of membrane RANKL or secreted by Tlymphocytes. Membrane-bound RANKL (mRANKL) or SRANKL binds to RANK via interaction with specific proteins: tumor necrosis factor receptor (TNFR)-associated factor (TRAF) proteins. TRAFs are signal transducers of an extensive variety of other receptor families, including innate immune receptors. Receptors of the TNF-R superfamily have open tissue distribution and regulate diverse biological functions. TRAFs bind to the intracellular domains of various receptors of the TNFR superfamily. One of the important roles of TRAFs in RANK-RANKL signaling is the activation of NFKBs, mitogen-activated protein kinases (MAPKs), and interferon-regulatory factors (IRFs). TRAF molecules may also contribute to chronic inflammation and infection (Xie, 2013).

OPG has also been noted to bind to TRAIL. TRAIL is expressed as a type II transmembrane protein. The extracellular domain of this protein can be cleaved proteolytically from the cell surface to act as a soluble cytokine. TRAIL acts by binding to 4 TRAIL receptors. The biological consequence of the TRAIL/OPG interaction is the inhibition of TRAIL-induced apoptosis in numerous cancer cells. This mechanism could lead to impaired apoptosis (Neville-Webbe, et al., 2004). The RANKL/RANK/TSP/TRIAL system is important but it appears that other signals expressed in tissues are implicated in the regulation, proliferation, and osteoblastic differentiation of calcifying vascular cells. 
In this context, IGF-1, IGF-2 and, IGF receptor (IGFR) signals appear to be critical for the homeostasis of cells, including VSMCs. The IGF system has been implicated in a range of diseases, including atherosclerosis, diabetic complications, cardiovascular diseases and cancer. IGF binding to the IGF-1 receptor results in the activation of a number of signaling pathways, including Ras/Raf/ERK and phosphatidyl inositol 3-kinase (PI3-k)/Akt. Calcium-induced OPG regulates IGF-1R expression in VSMCs, and protects against calcium-inducible calcification (Di Bartolo, et al., 2011). IGF-1R activity and expression modulate VSMC calcification. There is a feedback mechanism involving calcium signaling and regulation of IGF-1R expression via OPG. IGFs play a significant role in the physiology of ECs by promoting migration, and by inducing NO production. These actions are mediated by IGF receptors. IGF-1 acts as a vasodilator in vivo (Higashi, Sukhanov, Anwar, Shai, \& Delafontaine, 2010). Depletion of the IGF-1 receptor may contribute to EC apoptosis induced by advanced glycation end products (AGEs) (Pan, et al., 2014). ECs express IGF and insulin receptors (including the IGF-1 receptor) and are responsive to IGFs (Bach, 2015; Chisalita \& Arnqvist, 2004).

Concerning skeletal metabolism, IGF-1 is a potent regulator of bone homeostasis as reported previously. IGF-1 plays an important role in bone remodeling; it is produced by osteoclasts, osteoblasts, and osteocytes acting in an autocrine or paracrine manner (Fulzele \& Clemens, 2012; Wang, et al., 2006). Hormonal, immune, and metabolic pathways affect the dynamics of osteocyte turnover. Interestingly, it has been reported in recent studies that the gut microbiota could affect these pathways (Charles, Ermann, \& Aliprantis, 2015). Gut microbiota induce IGF-1 and thus promote bone formation and growth (Yan, et al., 2016). Manipulation of the microbiome with probiotics as a target in diseases is attracting major attention (Ejtahed, Soroush, Angoorani, Larijani, \& HasaniRanjbar, 2016).

\subsection{Biochemical crosstalk between endothelial cells and osteocytes}

Recent studies have elucidated the crosstalk between EC and osteoblasts during osteogenesis, thus coupling angiogenesis and osteogenesis. The mammalian skeleton supports stem and progenitor cells that permit lifelong hematopoiesis and osteogenesis; these processes rely on niche microenvironments. The ability of stem cells to reside within niches is important (Kusumbe, Ramasamy, \& Adams, 2014). Recent findings have identified the endothelial Notch as a key positive regulator of angiogenesis and osteogenesis in bone (Ramasamy, Kusumbe, Wang, \& Adams, 2014). Several factors contribute to the molecular interactions between ECs and osteogenic cells. Among endogenous factors, IGF-1, vascular endothelial growth factors (VEGFs), lipocalin -2(LCN2) and NO pathways have been the most widely studied. 


\subsubsection{IGF-1}

IGF-1 signaling regulates numerous physiological functions: metabolism, hypertrophy, senescence and apoptosis in the heart. IGF-1 deficiency is associated with an increased risk of cardiovascular disease, whereas cardiac activation of IGF-1 receptor (IGF-1R) protects against the harmful effects of a high-fat diet and myocardial dysfunction (Troncoso, Ibarra, Vicencio, Jaimovich, \& Lavandero, 2014). Calcium-induced OPG regulates IGF-1R expression (Di Bartolo, et al., 2011). Interestingly, OPGinducible IGF1R expression is biphasic: low (physiological) OPG concentrations were able to upregulate IGF-1R, while high (pathological) OPG mimic the high circulating OPG levels detected in patients with vascular disease (Di Bartolo, et al., 2011).

\subsubsection{VEGFs}

VEGFs promote EC survival by stimulating the formation of a multi-protein transmembrane complex that includes VEGF receptor 2 (VEGFR-2). VEGFs increase bone mass through a VEGFR 2- and PI3kinase-mediated pathway, which induces $\beta$-catenin transcriptional activity. This molecular mechanism exists in endothelial and osteoblastic cells. Earlier findings established that VEGF-induced effects were mediated by enhanced stabilization and transcriptional activity of $\beta$-catenin in endothelial and osteoblastic cells (Maes, et al., 2010).

\subsubsection{LCN2}

LCN2, also called neutrophil gelatinase-associated lipocalin (NGAL) and siderocalin, is mainly released from adipocytes. LCN2 is an adipokine with specific lipid-binding activity. It acts as a lipid chaperone to promote lipotoxicity in ECs. Elevated local levels of LCN2 participate in the pathogenesis of cardiovascular dysfunction (Wu, et al., 2014). Bone can be exposed to a variety of stresses, including trauma, loading and unloading. The adaptation of bone to unloading is regulated by coordinated molecular mechanisms. Recent studies have investigated the role of LCN2 as a new mechanoresponding gene that regulates bone homeostasis and could be involved in the initiation of osteoporosis induced by mechanical loading due, for instance, to aging (Rucci, et al., 2015). The role of LCN2 in bone metabolism is still unclear; however, it is now well demonstrated that LCN2 appears to be a useful clinical biomarker in inflammatory diseases in relationship with EC-osteoblast coupling (Veeriah, et al., 2016).

\subsubsection{Nitric oxide (NO)}

The recent advances in our understanding of osteogenesis have provided significant information about the role of NO in bone formation. Endothelial NO synthase (eNOS) is widely expressed in bone on a constitutive basis, whereas inducible NOS (iNOS) is expressed in response to inflammatory 
stimuli (van't Hof \& Ralston, 2001). Interestingly, proinflammatory cytokines, such as TNF- $\alpha$, IL-1 $\beta$, IL8, and IL-17, are involved in the up-regulation of iNOS expression in inflammatory bowel diseases.

NO produced by osteocytes and by the endothelium of the vessels integrated in bone is an important regulator of bone response to loading. In addition, NO is able to mediate osteoclast activity. Concerning the response to loading variations, recent results show that ECs and osteoblasts share the same key transcription factor, NF-KB. In ECs, NF-KB is directly activated by low mechanical strengths and induces NOS 2 and expression of the pro-inflammatory cytokine IL-1 $1 \beta$. In osteoblasts, NF-KB is activated by the IL-1 $\beta$ released by unloaded ECs and induces NOS (Veeriah, et al., 2016). Transcriptional responses are central to the maintenance of endothelial homeostasis during variations of blood flow including pulsatile flow and spatial-varying shear stress. Concerning the role of the vascular endothelium, shear stress has been implicated in the reactivation of developmental genes, implicating Wnt and Notch signaling, for vascular development and repair. The characteristics of hemodynamic shear forces, which modulate mechano-signal transduction, influence metabolic effects and thus vascular function (Lee, Packard, \& Hsiai, 2015). In this context of hemodynamic adaptation, ROS play a modulator role in ECs as signaling molecules to mediate various biological responses such as gene expression, cell proliferation, and senescence. The major sources of ROS in ECs are enzymes such a NADPH oxidase (NOX) and xanthine oxidase, and the mitochondria (Frey, Ushio-Fukai, \& Malik, 2009; Oudot, et al., 2006).

Another major role of $\mathrm{NO}$ in the vessel is in the regulation of calcium metabolism. Complex pathological mechanisms are involved in the dysfunction of calcium homeostasis that leads to the development of vascular calcification. As mentioned above, the mechanisms that regulate vascular calcification are complex. Vascular calcification and OP appear in aging, and during diseases such as diabetes mellitus and chronic kidney disease (CKD). Recent studies showed that NO inhibited VSMC calcification and osteoblastic differentiation of VSMCs (Kanno, et al., 2008; Veeriah, et al., 2016).

In the concept of EC-osteoblast crosstalk, one major challenge is perhaps to evaluate the importance of intercellular communication, which can be mediated through 1) direct cell-cell contact 2) transfer of secreted molecules, and 3) extracellular vesicles (EVs). Numerous studies have demonstrated that several bioactive molecules, such as microRNAs (miRNA), mRNAs, proteins and lipids, are trafficked with EVs. Very biological functions have been attributed to EVs (Raposo \& Stoorvogel, 2013). In serum and plasma, miRNAs are present in a highly stable, cell-free form and play important roles in bone homeostasis, such as the regulation of osteoblast and osteoclast differentiation. Some miRNAs have been identified as potential biomarkers in patients with postmenopausal osteoporosis (Tang, Xiong, Ge, \& Zhang, 2014). The identification and targeting of EV-associated miRNAs are emerging as a new therapeutic strategy in skeletal and vascular diseases. 


\section{5- Osteoprotegerin and pathophysiology}

\subsection{Approach via genetic manipulations in animal and human genetic data.}

The development of transgenic technologies in mice and rats has made it possible to study the consequences of genetic alterations using knockout or overexpression of specific genes on cardiovascular and metabolic functions. Particularly important has been the advance in knowledge of the role of OPG, RANKL and RANK via the selective targeting of genes and our understanding of interactions of different systems such as bone metabolism and cardiovascular functions. Overexpression of OPG in transgenic mice leads to profound osteopetrosis. Osteopetrosis is a disorder characterized by a defect in osteoclastic bone resorption. In contrast, in mice, ablation of the OPG gene causes severe osteoporosis. Suppression of RANK produces profound osteopetrosis, indicating the important physiological role of this protein in regulating bone resorption. OPGdeficient mice (OPG-/-) exhibited an overall decrease in total bone density and a high incidence of fractures (Bucay, et al., 1998; Simonet, et al., 1997). The central roles of RANKL and RANK in determining the level of bone resorption were demonstrated through the generation of transgenic mice: RANKL-/- and RANK-/- mice were osteopetrotic due to the absence of osteoclasts (Blair, Zhou, Seibel, \& Dunstan, 2006). OPG protein and transgenic overexpression of OPG in OPG-/- mice rescued the osteoporotic bone phenotype observed in OPG-deficient mice. However, intravenous injection of recombinant OPG over a 4-wk period could not reverse the arterial calcification observed in OPG-/- mice (Min, et al., 2000). Renal and aortic calcification is observed in OPG knockout mice, indicating that OPG protects large blood vessels against medial calcification (Bucay, et al., 1998).

Concerning cardiac disease associated with ageing, both 2.5- and 12-month-old OPG-/- mice, presented a higher systolic blood pressure and a greater heart weight/body weight ratio than agematched WT mice; suggesting that OPG plays a role in preserving heart structure and its evolution with ageing (Hao, et al., 2016). Evidence indicates that the OPG/RANK/RANKL triad also plays a role in the cardiovascular system (Bucay, et al., 1998). In hypercholesterolemic Ldlr -/- mice, exogenous OPG does not inhibit the development of atherosclerosis, but prevents calcification of the aorta (Morony, et al., 2008). Hypercholesterolemic Ldlr(-/-) ApoB (100/100) mice develop calcific aortic stenosis and valvular cardiomyopathy in old age. Exogenous OPG protects aortic valve function in these genetic mice, which develop calcific aortic stenosis. Mechanisms by which OPG reduces valve calcification can be deduced from its inhibition of RANK/RANKL signaling (Weiss, et al., 2013). In conclusion, genetic manipulations demonstrated that OPG-/-mice developed vascular calcification of large arteries associated with osteoporosis and cardiovascular diseases; the injection of recombinant OPG partly reversed these actions. 
In recent years, mutations causing severe alterations in bone density were identified in groups of patients. Moreover, evaluation of the presence of polymorphisms and their effects on bone tissue in postmenopausal women provided insights into the pathophysiology of osteoporosis. The association of the polymorphisms associated with bone mineral density has been investigated in various studies. In patients with $1181 \mathrm{GC}$ polymorphism, it has been demonstrated that a change in nucleotides was related to the impaired secretion of OPG (Boron, et al., 2015).

Similar findings have been observed in the chronic bone disorder, Paget's disease; it is a common disease of the bone associated with abnormal bone turnover due to an imbalance between osteoclastic and osteoblastic activity. The disorder is associated with excessive bone resorption, followed by skeletal deformity. Most patients with juvenile Paget's disease are homozygous for mutations in the TNFRSF11B gene, which results in a deficiency of OPG (Naot, et al., 2014).

\subsection{OPG: an inhibitory factor of osteoclastogenesis}

In the aged population, osteoporosis is a major cause of fractures and associated morbidity. Its pathogenesis is multifactorial: chronic inflammation and endocrine mechanisms, associated with alterations of the immune system. Osteoporosis results from a predominance of osteoclast over osteoblast activity. Numerous studies demonstrated the importance of OPG in protecting against bone resorption in bone-related diseases (Boron, et al., 2015; Pietschmann, Mechtcheriakova, Meshcheryakova, Foger-Samwald, \& Ellinger, 2016). The OPG/RANKL/RANK axis has been identified as a candidate mediator for paracrine signaling in bone metabolism. OPG prevents calcification but is not able to reverse vascular calcification once it has occurred.

As we reported previously, the OPG/RANKL/RANK triad plays an important function in osteogenesis and the expression of RANKL in bone cells is stimulated by various cytokines, hormones such as PTH, estrogens and 1,25 dihydroxy-vitamin D3. Concerning female hormones, there is clear evidence of the relationship between estrogen deficiency and an accelerated loss of bone mass. RANKL expression in B lymphocytes, but not T lymphocytes, contributes to the loss of trabecular bone caused by estrogen deficiency (Manolagas, O'Brien, \& Almeida, 2013). The presence of nuclear estrogen receptors in human osteoblasts has been proven. Two types of estrogen receptors (ERs) have been described: receptor $\alpha(E R-\alpha)$ and receptor $\beta$ (ER- $\beta$ ). Estradiol stimulates OPG expression in osteoblasts via ER $\alpha$ (Wilson \& Westberry, 2009).

Concerning postmenopausal osteoporosis, studies have been performed to determine whether an association exists between serum OPG levels and BMD in postmenopausal women. Serum OPG was found to be independently associated with osteoporosis and the presence of vertebral fractures (Mezquita-Raya, et al., 2005). The selective-estrogen receptor modulator, raloxifene, is able to 
increase OPG serum levels in postmenopausal women with low BMD (Messalli, et al., 2007). In conclusion, the protective role of OPG was demonstrated by its protective action against bone resorption in the bone-related diseases of postmenopausal women.

In the protective role of OPG against bone resorption, it is important to consider the mechanisms of osteoblastic differentiation into osteocytes. Several key proteins, such as sclerostin, fibroblast growth factor-23 (FGF-23) and the tandem: Wnt/ $\beta$-catenin, have been identified. The glycoprotein sclerostin has been characterized as a negative regulator of bone growth (Moester, Papapoulos, Lowik, \& van Bezooijen, 2010). The importance of Wnt signaling for bone has also been highlighted. Wnt signaling represses bone resorption through the increased secretion of OPG (Baron \& Kneissel, 2013; Joiner, Ke, Zhong, Xu, \& Williams, 2013; Kramer, et al., 2010) (Figure 4).

Wnt proteins are secreted cysteine-rich glycoproteins. The $\mathrm{Wnt} / \beta$-catenin pathway plays an important role in the main processes that control osteogenesis. In the absence of Wnt stimulation, cytoplasmic $\beta$-catenin is phosphorylated and degraded by the ubiquitin-proteasome system. Upon binding of Wnt, phosphorylation of $\beta$-catenin is blocked, thus allowing it to translocate to the nucleus where it complexes with transcription factors to upregulate Wnt target gene transcription (V. S. Li, et al., 2012). Wnt binds to a member of the Frizzled family of seven-transmembrane proteins, and to a low-density lipoprotein-related receptor (LRP): LRP 4, 5 or 6, leading to downregulation of GSK-3 activity and the initiation of the $\mathrm{Wnt} / \mathrm{\beta}$-catenin signaling cascade. LRP5 and LRP6 were originally identified thanks to their homology to the low-density lipoprotein (LDL) receptor (Joiner, et al., 2013)

This pathway regulates the gene transcription of proteins that are important for osteogenic differentiation. It is also involved in regulation of the mature skeleton. As we reported previously, Rspondins have been recognized as modulators of the skeleton. R-spondins are a family of proteins acting as agonists of the $\mathrm{Wnt} / \beta$-catenin signaling pathway. Leucine-rich repeats containing G-proteincoupled receptors (LGR4/5/6) have been identified as the new receptors of R-spondins (Shi, Mao, Zheng, \& Jiang, 2016). Concerning anabolic aspects, bone biology research showed that osteocytes produce inhibitors of the anabolic Wnt signaling pathway; there are a number of extracellular Wnt antagonists (Kubota, Michigami, \& Ozono, 2009). Recently, it has been reported that LGR4, also called GPR48 (G-protein-coupled receptor 48), is a receptor for RANKL and inhibits osteoclast differentiation in vivo; the soluble LGR4 extracellular domain (ECD) binding RANKL. The importance of LGR4 and its ligands, in the regulation of Wnt signaling pathways has been established in both in vitro and in vivo studies using experimental models and human genetics analysis. Finally, LGR4 acts as a RANKL receptor that negatively regulates osteoclast differentiation and bone resorption (Luo, et al., 2016). These pathways are now the target for therapeutic intervention. 


\section{6- Osteoprotegerin in cardio-metabolic disorders}

\subsection{Implication of the OPG/RANK/RANKL in heart diseases: heart failure and atrial fibrillation}

In various experimental models of heart failure, significantly increased mRNA expression of OPG was noted in both the ischemic and non-ischemic myocardium compared with that in subjects without heart failure. These results demonstrated a possible role of OPG in the adaptation of the myocardium to the failure. The OPG/RANK/RANKL axis appears activated within the myocardium in the rat model of post-infarction heart failure. In cardiomyocytes, enhanced systemic expression of RANKL was accompanied by increased expression of the receptor RANK. These findings suggest a potential role for RANKL/RANK interaction in the pathogenesis of heart failure (Ueland, et al., 2005). Human subjects with heart failure had significantly increased serum levels of OPG compared with healthy controls (Ueland, et al., 2005). In a prospective study, it has been reported that serum OPG was directly associated with a higher probability of death or readmission for acute heart failure within 6 months, irrespective of other known prognostic markers. These findings were observed both when the ejection fraction was preserved or reduced (Frioes, et al., 2015). A significant interaction was observed between OPG and NT-proBNP. A combination of high levels of both OPG and NTproBNP, compared with a combination of low levels, was associated with a fivefold increased risk of heart failure. This is observed in male patients. Paradoxically, in women, no associations were observed. In contrast, in women, higher OPG levels were positively associated with the prevalence of hypertension, whereas body mass index (BMI) was inversely related to OPG levels (di Giuseppe, et al., 2017).

The pathophysiological alterations underlying the initiation and progression of atrial fibrillation (AF) are dependent on multiple factors. They are associated with structural and electrical remodeling in cardiomyocytes of different area of the myocardium; cardiac fibroblasts are also implicated in these processes. Cardiac fibroblasts are well-established as key regulators of extracellular matrix turnover in the context of myocardial remodeling and the fibrosis associated with inflammatory process; various inflammatory cytokines and chemokines being up-regulated in AF (Dzeshka, Lip, Snezhitskiy, \& Shantsila, 2015; Jalife, 2014). Among the cytokines, the role of TNF in inflammation has been extensively investigated. In this context, the potential relationship between levels of OPG or TRAIL, and arrhythmias has been explored. The first study in this field was based on the population of the Framingham Offspring Study. Among the 12 inflammatory markers tested, only OPG had a significant prognostic value in predicting the occurrence of AF (Schnabel, et al., 2009). It appears that OPG and TRAIL may contribute to the pathogenesis of AF as negative and positive factors, respectively (Rewiuk \& Grodzicki, 2015). One study showed that the OPG/RANK/RANKL triad is involved in the development and progression of $\mathrm{AF}$, this axis being, as we reported, implicated in regulating atrial 
structural remodeling. AF groups had higher atrial gene expression of the OPG/RANK/RANKL axis and a higher RANKL/OPG ratio, particularly in paroxysmal AF (H. Cao, et al., 2011).

TRAIL triggers non-apoptotic signals in normal cells. But apoptotic signal in several pathologic conditions. Systemic TRAIL delivery significantly reduced cardiac fibrosis and apoptosis in a mouse model of diabetic cardiomyopathy (Toffoli, et al., 2012). TRAIL initiates pathways of cell death in which caspases activation in mediated either directly or indirectly via the release of apoptogenic factors from mitochondria. TRAIL induces apoptosis through the death receptors DR4/R1 and DR5/R2, which are expressed on the surface of target cells. In preclinical models, TRAIL showed anticancer activity (Labovsky, Vallone, Martinez, Otaegui, \& Chasseing, 2012). In one hypothesis, the uptake and binding of TRAIL by OPG is a protective mechanism against apoptosis (Pritzker, Scatena, \& Giachelli, 2004).

In conclusion, taken together, these results suggest that mediators of bone metabolism play a potential role in the initiation and development of $A F$ via activation of the OPG/RANK/RANKL axis $(H$. Cao, et al., 2013).

\subsection{OPG plays a significant role in the physiology of endothelial cells}

OPG enhances both VSMC and EC -survival. It directly promotes both the proliferation and migration of microvascular ECs (Cross, et al., 2006). OPG is localized to WPBs and co-localized with the adhesion molecule P-selectin and the glycoprotein vWF. OPG is physically associated, as reported above, with vWF within the Weibel-Palade bodies (WPBs) of ECs and also in plasma. OPG binds with high affinity to VWF reductase, and TSP-1, and may provide a link between TSP-1 and VWF. Treatment of human umbilical vein endothelial cells with pro-inflammatory cytokines, such as TNFalpha and IL-1beta, resulted in mobilization from the WPBs and subsequent secretion of OPG protein into the culture supernatant (Zannettino, et al., 2005). In vivo, the interaction between OPG and vWF is maintained in the serum after secretion, where OPG may act to regulate the hemostatic role of VWF. OPG may also serve to modulate the extent of the inflammatory response. It can act as a survival and antiapoptotic factor for ECs (Schoppet, et al., 2004). Besides, OPG increases EC proliferation in microvessels promoting neovascularization (McGonigle, Giachelli, \& Scatena, 2009).

OPG has been proposed as a marker of endothelial dysfunction in early pathophysiological events. An independent positive association between OPG and asymmetric dimethylarginine (ADMA), and between OPG and arterial stiffness assessed by pulse wave velocity (i.e. both markers of endothelial dysfunction), has been reported in hypertensive patients (Tsioufis, et al., 2011). OPG has been shown to induce the expression of intercellular adhesion molecule-1 (ICAM-1), vascular adhesion molecule-1 
(VCAM-1), and E-selectin on ECs and to promote leukocyte adhesion, an early step in EC dysfunction, thus supporting a pro-atherosclerotic role of OPG (Zauli, et al., 2007).

The existence of actions of the RANKL/RANK/OPG system in the endothelium suggests that it may have specific functions in vascular regulation (Figure 2). Numerous findings have demonstrated RANKL expression on endothelial and inflammatory cells (Riegel, et al., 2012). RANKL significantly increased the activity of matrix metalloprotease (MMP) in VSMCs. OPG neutralizes the effect of RANKL on the induction of MMP activity in VSMCs by inhibiting its binding to RANK (Quercioli, et al., 2012; Venuraju, et al., 2010). MMPs and endogenous processes, such as disturbances in mineral and hormonal metabolism, play a significant role in the initial steps of vascular calcification.

\section{7- Positive relationship between circulating osteoprotegerin, vascular damage, and metabolic diseases}

It is now recognized that OPG exerts proatherogenic and prodiabetogenic effects. OPG participates in the pathogenesis of atherosclerosis and cardiovascular diseases by amplifying the adverse effects of inflammation. Serum levels of OPG were measured in patients with cerebrovascular disease, stable angina, and CAD. However, no constant correlation was observed between OPG levels and the evolution of the CAD (Schoppet, et al., 2003). OPG levels were independently associated with cardiovascular mortality, but not bone mineral density in patients suffering from cerebrovascular diseases (Browner, Lui, \& Cummings, 2001). Experimental studies have evaluated the possible relationship between OPG, vascular fibrosis, markers of inflammation and fibrosis, such as fibronectin, collagen I, III, IV and transforming growth factor- $\beta 1$ (TGF- $\beta 1$ ). In ApoE(-/-) mice, recombinant human OPG induced signs of fibrosis and up-regulated the arterial expression of TGF$\beta 1$, thus supporting the pathogenic role of OPG in the initiation of atherosclerotic lesions (Toffoli, et al., 2011). OPG also influences the production of other agents implicated in plaque stability, such as matrix metalloproteinases. OPG is able to stimulate metalloproteinase activity in VSMCs. In a study investigating inflammatory processes in an EC culture, OPG was triggered by inflammatory cytokines, thus leading to the expression of EC adhesion molecules (Mangan, Van Campenhout, Rush, \& Golledge, 2007). This process is described in mitral valve prolapse (MVP). Circulating OPG levels were higher in MVP patients than in controls, which supports the hypothesis that OPG is involved in MVP development and progression (Songia, et al., 2016).

The association of different markers, and in particular OPG, with diabetic and metabolic syndrome (MetS) complications is now demonstrated. Multiple signaling pathways contribute to the adverse effects of glucotoxicity on cellular functions (Rochette, et al., 2014). In the experimental context of 
MetS, circulating and tissue levels of OPG were significantly increased in C57BL6 mice fed a high-fatdiet (HFD), which is an animal model for the study of MetS. OPG may trigger proinflammatory changes in adipose tissue in MetS/HFD-induced obesity (Bernardi, et al., 2014).

Many studies have reported that serum OPG is significantly increased in diabetic patients. In a large observational study, plasma concentrations of OPG were higher in diabetic than in non-diabetic subjects (Browner, et al., 2001; Knudsen, et al., 2003; Rasmussen, Tarnow, Hansen, Parving, \& Flyvbjerg, 2006). It has been suggested that the increased levels of OPG could reflect vascular damage in diabetic patients. Diabetic angiopathy is associated with linear media calcifications and it is a long-term process. As reported above, the mechanisms implicated in the development of calcifications are not precisely known. Plasma OPG levels were significantly increased only in patients with microvascular complications, suggesting that elevated plasma levels of OPG may reflect microvascular damage (Knudsen, et al., 2003; Rasmussen \& Ledet, 2005). Plasma OPG was higher in patients with than in those without diabetic nephropathy; OPG levels increasing with decreased kidney function. In addition, independent positive correlations were demonstrated between plasma OPG and kidney function, HbA1c and systolic blood pressure (Rasmussen, et al., 2006).

Concerning obesity and MetS, their relationships with bone metabolism are complex. Obesity is traditionally viewed as favorable to bone health. The increased circulating and tissue levels of proinflammatory cytokines in obesity may promote osteoclast activity and bone resorption by modifying the receptor activator of the NF-KB (RANK)/RANK ligand/OPG pathway (J. J. Cao, 2011). In a clinical study, serum concentrations of OPG were significantly lower in obese patients than in normal-weight controls (Holecki, et al., 2007). It has been confirmed that circulating levels of OPG are lower in obese subjects without diabetes mellitus and are negatively associated with body mass index (BMI), and waist circumference (Ashley, et al., 2011). However, previous results showed that in a healthy obese population, OPG was not associated with BMI and the lipid profile (Gannage-Yared, et al., 2008). This relationship has been the subject of controversial studies. The absence of a relationship between BMI and OPG has been reported in other studies (Oh, et al., 2005; Uemura, et al., 2008). More recently, the relationship between lipid profile and OPG levels in obese and non-obese women has been investigated. Age significantly correlated with OPG levels. After adjustment for age, only HDL-C levels, LDL-C levels, and HOMA-IR correlated with OPG levels in obese, but not non-obese women. Finally, the human studies did not resolve whether OPG should be regarded as being associated with a protective mechanism or instead indeterminate with respect to vascular disease progression (Ayina Ayina, et al., 2015). 


\section{8- OPG as a potential therapeutic agent}

The homeostasis process concerning OPG and RANKL plays an essential role in the pathophysiology of bone. As we reported, several studies have demonstrated the beneficial effect of OPG as a specific therapeutic agent against bone resorption as well as against arterial calcification in cardiovascular disorders. Advanced clinical trials are underway. New specific targets for the treatment of bone loss are based on the inhibition of bone resorption by osteoclasts or the stimulation of bone formation by osteoblasts.

\subsection{OPG and bone diseases}

As related above, bone resorption is primarily due to the activation of osteoclastogenesis and an increase in receptor activator of RANKL expression. First, OPG, used as a therapy to block RANKL, was initially successful and antibodies against OPG were developed (Tella \& Gallagher, 2014). A recombinant OPG fusion protein (Fc-OPG) has been used in experimental studies. It has been employed in rat models to treat arthritis and in dogs, where it induced an increase in bone formation and enhanced healing (Bolon, Campagnuolo, \& Feige, 2002; Yao, et al., 2011).

In clinical trials of patients with osteoporosis, inhibition of RANK-L reduced bone loss. The human monoclonal antibody against RANK-L (Denosumab) has been approved for the treatment of osteoporosis (Tarantino, et al., 2013). Denosumab targets RANKL by binding to RANKL, this drug prevents the maturation and differentiation of preosteoclasts and promotes apoptosis of osteoclasts (Figure 5). In the FREEDOM study, denosumab given twice yearly for 36 months was shown to reduce the risk of new radiographic vertebral fractures by $68 \%$, hip fractures by $40 \%$, and non-vertebral fractures by $20 \%$ when compared to placebo (Cummings, et al., 2009). Several treatments, including bisphosphonates, teriparatide (a recombinant fragment of PTH: rhPTH-1-34), raloxifene and denosumab, are available for osteoporosis and fracture prevention. The superiority of denosumab over bisphosphonates in increasing BMD could be explained by its greater antiresorptive effect (Beaudoin, et al., 2016). The potential uses of RANKL inhibitors have been explored extensively in preclinical studies. Antibodies targeting RANKL preserve bone mass and strength in preclinical models (Lacey, et al., 2012).

Previously in this review, we reported that the glycoprotein, sclerostin secreted by osteocytes, was a negative regulator of bone growth. Sclerostin is an endogenous protein that inhibits osteoblast differentiation by binding to the LRP receptors. In this field, the use of sclerostin antibodies showed promising results. Anti-sclerostin antibodies such as romosozumab and blosozumab are alternative drugs. These monoclonal antibodies, which bind sclerostin, increased bone formation and decreased bone resorption. Sclerostin is now recognized as a target for osteoporosis therapy (Choi, et al., 2017; Cosman, et al., 2016). 
Concerning the relationship between bone homeostasis and the effects of hormones, it has been proved that estrogen deficiency induced an accelerated loss of bone mass. The antiresorptive effect of estrogens on bone has been used in the treatment of postmenopausal osteoporosis. The selectiveestrogen receptor modulator, raloxifene, is able to increase OPG serum levels in postmenopausal women with low BMD (Messalli, et al., 2007).

A relationship has been reported between heparin, OPG, and bone metabolism (Theoleyre, et al., 2006). Although OPG is known to bind heparin with low nanomolar affinity, in vivo studies with intravenous heparin infusions in healthy individuals showed a 2.2 fold increase in the circulating OPG levels within $5 \mathrm{~min}$ as compared to pre-injection values. However, the OPG levels were significantly decreased or normalized within 1 hour (Nybo \& Rasmussen, 2008). Heparin enhances bone resorption and induces bone loss. The results suggest that heparin promotes osteocyte-modulated osteoclastogenesis in vitro by inhibiting OPG activity (B. Li, Lu, Chen, Zhao, \& Zuo, 2016).

\subsection{OPG and therapies of vascular calcification}

Vascular calcification is strongly associated with cardiovascular disease and mortality, particularly in high-risk patients with diabetes and CKD. As reported above, it has a variety of forms, including intimal calcification and medial calcification, but can also be observed in the valves of the heart. Vascular calcification is a cell-mediated process associated with VSMC death and phenotypic changes that promote vascular calcification. These processes may play a role in the accelerated vascular calcification observed in patients with CKD (Shanahan, 2013).

A variety of therapies have been tested to attempt to prevent or diminish vascular calcification. Therapies for treating vascular calcification under investigation include agents proposed as osteoporosis therapies: OPG, bisphosphonates, denosumab and teriparatide. Bisphosphonates are synthetic derivatives of pyrophosphate. There are two classes of bisphosphonates, the $\mathrm{N}$-containing and, non- $\mathrm{N}$-containing bisphosphonates. The presence of a nitrogen atom in the side chain in the byproducts such as alendronate, pamidronate or ibandronate, enhances their affinity for bone tissue. Bisphosphonates reduce arterial wall calcification but have no effect on arterial stiffness or on cardiovascular events (Kranenburg, et al., 2016).

As RANKL is thought to promote vascular muscle cell calcification, RANKL inhibition by specific agents, such as denosumab, have been tested for their ability to prevent vascular calcification (Panizo, et al., 2009). In a mouse model of glucocorticoid-induced diseases, denosumab reduced the amount of calcium deposited in the aorta (Helas, et al., 2009). Experimental studies demonstrated that denosumab inhibited the induced calcium deposition to basal levels in porcine valve interstitial cell culture. As reported above, calcific aortic valve disease is an actively regulated and progressive disease, characterized by a cascade of cellular changes leading to significant aortic valve stenosis. 
Denosumab may be a novel therapeutic approach for the clinical treatment of diseased valves (Lerman, Prasad, \& Alotti, 2015).

\subsection{OPG and metabolic diseases}

Results emerging from in vitro, in vivo, and clinical studies indicate that regulatory glycoproteins, OPG, RANKL and TRAIL, are related to metabolic diseases. As reported above, numerous studies found an association between OPG and diabetes. It has been established that circulating OPG is lower in obese subjects without diabetes mellitus and is negatively associated with body weight and BMI (Ashley, et al., 2011). In contrast, the results also showed that in a healthy obese population, OPG was not associated with the BMI or lipid profile. Recent studies have shown that OPG levels in patients with type 1 diabetes mellitus were significantly higher than those in healthy controls. In addition, plasma OPG levels positively correlated with diabetic neuropathy (Terekeci, et al., 2009). Insulin resistance in obesity is associated with decreased serum OPG levels (Ugur-Altun, Altun, Gerenli, \& Tugrul, 2005). In a prospective observational follow-up study, elevated plasma OPG was a strong and independent predictor of all-cause mortality (Reinhard, et al., 2010). But an increased OPG level could also be an indicator of a proinflammatory process; a process that connects osteoporosis, vascular calcification, and inflammation.

Interferences exist between OPG and treatments for metabolite diseases such as glitazones, and, statins. OPG levels significantly decreased in both type 1 and type diabetes after six months of treatment with insulin or pioglitazone. However, metformin treatment for the same time did not modify OPG concentrations (Perez de Ciriza, Lawrie, \& Varo, 2015). Statin therapy improves lipid profiles and reduces vascular inflammation. Atorvastatin reduced not only carotid-femoral pulse wave velocity (PWV) at low or high doses, but also high sensitivity C-reactive protein (hSCRP) and OPG levels; the reduction in PWV correlated with the reduction in OPG (Davenport, et al., 2015). In a recent study, atorvastatin treatment $(40 \mathrm{mg} /$ day for 3 months ) led to a reduction in circulating osteoprogenitor cells and RANKL expression in T cells, as well as an increase in serum OPG levels (Rattazzi, et al., 2016). The effect of statins on bone formation is related to the increased gene expression of bone morphogenetic protein in osteoblasts. In these cells, atorvastatin induced an almost three-fold increase in the production of OPG mRNA (Estanislau, et al., 2015; Viereck, et al., 2005). Together, these data suggest that statins could have protective effects in the bone-vascular axis. 


\section{9- Osteoprotegerin as a new biomarker}

In recent years, new approaches are being used to search for novel biomarkers. A "Biomarker is a characteristic that is objectively measured and evaluated as an indication of normal biologic processes, pathogenic processes, or pharmacologic responses to a therapeutic intervention"; the term also covers traditional risk factors (Biomarkers Definitions Working, 2001). Measurements of biomarkers are frequently used in cardio-metabolic medicine and are recognized for the value they add to the diagnosis and prognosis of various diseases.

Among the hundreds of molecules of major significance analyzed, there are markers of inflammation, including the superfamily of tumor necrosis factor (TNF) receptors. Serum OPG (and SRANKL) levels have been proposed as biomarkers of vascular risk and prognosis in a variety of cardiovascular and metabolic diseases. However, the results in this field are inconsistent (Perez de Ciriza, et al., 2014; Shetelig, et al., 2017).

Cardiotrophin-1, soluble endoglin, suppression of tumorigenicity 2 (ST2): a member of the IL 1 receptor family, growth differentiation factor-15 (GDF-15), galectin-3 and other new markers associated with heart disease have been identified. However, current data on the relationship between these biomarkers and left or right ventricular dysfunction are still limited (Meluzin \& Tomandl, 2015). OPG appears to be a new emerging biomarker, which, in recent clinical trials, has been associated with both the progression and severity of cardiac disease.

OPG, as well as RANKL, has also been found within atherosclerotic carotid plaques as well as in thrombus material obtained at the site of plaque rupture during myocardial infarction (Sandberg, et al., 2006). OPG has been identified as an independent predictor of heart failure development and mortality in patients with acute coronary syndrome (Omland, et al., 2008) and a positive correlation has been found between OPG serum levels and disease severity (Montagnana, Lippi, Danese, \& Guidi, 2013; Schoppet, et al., 2003; Van Campenhout \& Golledge, 2009; Venuraju, et al., 2010). Raised serum OPG levels have been associated with the presence and the severity of coronary atherosclerosis in studies of CAD patients undergoing coronary angiography, and elevated serum OPG concentrations have been found to correlate with the severity of peripheral artery disease (Kiechl, et al., 2004; Ziegler, Kudlacek, Luger, \& Minar, 2005).

Higher serum OPG levels have been reported in patients with ST-elevation myocardial infarction (STEMI) than in patients with non-STEMI, and controls. In the same way, several clinical studies have shown a negative impact of circulating OPG levels on outcomes in stable coronary artery disease (Crisafulli, et al., 2005; Fuernau, et al., 2013). It is not easy to establish a temporal profile of OPG in STEMI, or to investigate possible associations between OPG measured during acute STEMI and final infarct size, microvascular obstruction or myocardial salvage. It is therefore likely that the high OPG levels measured early in STEMI patients reflect the effect of heparin, and not the ischemic injury 
(Shetelig, et al., 2017). Finally, the results of recent studies investigating OPG and infarct size in STEMI patients have been inconsistent.

Concerning the development of pulmonary arterial hypertension (PAH) and the prediction of disease severity; OPG has prognostic utility. OPG elevation is associated with heart failure in patients who developed PAH (Zhang, et al., 2015). These results suggest that OPG may play a role in the development of pulmonary vascular dysfunction in patients with heart failure. Immunohistochemistry of vascular lesions in human PAH demonstrated increased OPG expression (Lawrie, et al., 2008). These changes correlated with prognostic markers and survival (Condliffe, et al., 2012).

Sustained release of OPG from vascular endothelial cells has been demonstrated in response to inflammatory proteins and cytokines, suggesting that OPG plays a modulatory role in vascular injury, inflammation and hemostasis (Figure 5). Therefore it is possible that OPG could have a new function as a potential biomarker in early endothelial dysfunction (Berezin, et al., 2015).

It is also suggested that a chronic persistent inflammatory state may reflect adverse left ventricular remodeling and that biomarkers measured late after myocardial infarction may mediate mechanisms other than acute necrosis. Subsequent studies may provide further insights into the complex interrelations between functional vascular changes, atherosclerosis and inflammation in relationship with disordered calcium balance and homeostasis.

\section{0- Conclusion}

Several investigations carried out in large populations have demonstrated that an increased release of OPG is associated with increased cardiovascular risk. It has also been suggested that increased OPG levels resulting from vascular damage correspond to a protective mechanism. OPG levels could lead to a faster diagnosis of cardiovascular diseases and thus an improved prognosis. However, it remains unclear whether OPG is a marker or rather plays a causal role in mediating or protecting against vascular injury. In summary, OPG may be a new promising marker for risk prediction in cardiovascular diseases. There is significant interest in developing OPG as a biomarker once the conditions of OPG measurement and the analytical items of variability have been defined. Much of the evidence collected from biomarker studies must be complemented by the significance of observed changes in the relationships between the biomarker and cofactors, such as the chronic inflammatory state and therapeutics. 


\section{Conflict of interest statement}

The authors declare that there are no conflicts of interest.

\section{Acknowledgments}

This work was supported by grants from French Ministry of Research, INSERM (Institut national de la santé et de la recherche médicale) and, from the Regional Council of Burgundy (Conseil Régional de Bourgogne), FEDER and Association de Cardiologie de Bourgogne. The authors have no other relevant affiliations or financial involvement with any organization or entity with a financial interest in or financial conflict with the subject matter or materials discussed in the manuscript apart from those disclosed. The authors wish to thank Martine Goiset for secretarial assistance and Philip Bastable for English assistance. 


\section{References}

Alderson, H. V., Ritchie, J. P., Middleton, R., Larsson, A., Larsson, T. E., \& Kalra, P. A. (2016). FGF-23 and Osteoprotegerin but not Fetuin-A are associated with death and enhance risk prediction in non-dialysis chronic kidney disease stages 3-5. Nephrology (Carlton), 21, 566-573.

Arko, B., Prezelj, J., Kocijancic, A., Komel, R., \& Marc, J. (2005). Association of the osteoprotegerin gene polymorphisms with bone mineral density in postmenopausal women. Maturitas, 51, 270-279.

Ashley, D. T., O'Sullivan, E. P., Davenport, C., Devlin, N., Crowley, R. K., McCaffrey, N., Moyna, N. M., Smith, D., \& O'Gorman, D. J. (2011). Similar to adiponectin, serum levels of osteoprotegerin are associated with obesity in healthy subjects. Metabolism, 60, 994-1000.

Ayina Ayina, C. N., Sobngwi, E., Essouma, M., Noubiap, J. J., Boudou, P., Etoundi Ngoa, L. S., \& Gautier, J. F. (2015). Osteoprotegerin in relation to insulin resistance and blood lipids in subSaharan African women with and without abdominal obesity. Diabetol Metab Syndr, 7, 47.

Bach, L. A. (2015). Endothelial cells and the IGF system. J Mol Endocrinol, 54, R1-13.

Baron, R., \& Kneissel, M. (2013). WNT signaling in bone homeostasis and disease: from human mutations to treatments. Nat Med, 19, 179-192.

Baud'huin, M., Duplomb, L., Teletchea, S., Lamoureux, F., Ruiz-Velasco, C., Maillasson, M., Redini, F., Heymann, M. F., \& Heymann, D. (2013). Osteoprotegerin: multiple partners for multiple functions. Cytokine Growth Factor Rev, 24, 401-409.

Bauer, E. M., Qin, Y., Miller, T. W., Bandle, R. W., Csanyi, G., Pagano, P. J., Bauer, P. M., Schnermann, J., Roberts, D. D., \& Isenberg, J. S. (2010). Thrombospondin-1 supports blood pressure by limiting eNOS activation and endothelial-dependent vasorelaxation. Cardiovascular Research, 88, 471-481.

Baum, M., Schiavi, S., Dwarakanath, V., \& Quigley, R. (2005). Effect of fibroblast growth factor-23 on phosphate transport in proximal tubules. Kidney Int, 68, 1148-1153.

Beaudoin, C., Jean, S., Bessette, L., Ste-Marie, L. G., Moore, L., \& Brown, J. P. (2016). Denosumab compared to other treatments to prevent or treat osteoporosis in individuals at risk of fracture: a systematic review and meta-analysis. Osteoporos Int, 27, 2835-2844.

Benslimane-Ahmim, Z., Poirier, F., Delomenie, C., Lokajczyk, A., Grelac, F., Galy-Fauroux, I., Mohamedi, A., Fischer, A. M., Heymann, D., Lutomski, D., \& Boisson-Vidal, C. (2013). Mechanistic study of the proangiogenic effect of osteoprotegerin. Angiogenesis, 16, 575-593.

Berezin, A. E., Kremzer, A. A., Martovitskaya, Y. V., Samura, T. A., Berezina, T. A., Zulli, A., Klimas, J., \& Kruzliak, P. (2015). The utility of biomarker risk prediction score in patients with chronic heart failure. Int J Clin Exp Med, 8, 18255-18264.

Bernardi, S., Fabris, B., Thomas, M., Toffoli, B., Tikellis, C., Candido, R., Catena, C., Mulatero, P., Barbone, F., Radillo, O., Zauli, G., \& Secchiero, P. (2014). Osteoprotegerin increases in metabolic syndrome and promotes adipose tissue proinflammatory changes. Mol Cell Endocrinol, 394, 13-20.

Biomarkers Definitions Working, G. (2001). Biomarkers and surrogate endpoints: preferred definitions and conceptual framework. Clin Pharmacol Ther, 69, 89-95.

Blair, J. M., Zhou, H., Seibel, M. J., \& Dunstan, C. R. (2006). Mechanisms of disease: roles of OPG, RANKL and RANK in the pathophysiology of skeletal metastasis. Nat Clin Pract Oncol, 3, 4149.

Bolon, B., Campagnuolo, G., \& Feige, U. (2002). Duration of bone protection by a single osteoprotegerin injection in rats with adjuvant-induced arthritis. Cell Mol Life Sci, 59, 15691576.

Boron, D., Kotrych, D., Bartkowiak-Wieczorek, J., Uzar, I., Bogacz, A., \& Kaminski, A. (2015). Polymorphisms of OPG and their relation to the mineral density of bones in pre- and postmenopausal women. Int Immunopharmacol, 28, 477-486. 
Brandstrom, H., Stiger, F., Lind, L., Kahan, T., Melhus, H., \& Kindmark, A. (2002). A single nucleotide polymorphism in the promoter region of the human gene for osteoprotegerin is related to vascular morphology and function. Biochem Biophys Res Commun, 293, 13-17.

Browner, W. S., Lui, L. Y., \& Cummings, S. R. (2001). Associations of serum osteoprotegerin levels with diabetes, stroke, bone density, fractures, and mortality in elderly women. J Clin Endocrinol Metab, 86, 631-637.

Bucay, N., Sarosi, I., Dunstan, C. R., Morony, S., Tarpley, J., Capparelli, C., Scully, S., Tan, H. L., Xu, W., Lacey, D. L., Boyle, W. J., \& Simonet, W. S. (1998). Osteoprotegerin-deficient mice develop early onset osteoporosis and arterial calcification. Genes Dev, 12, 1260-1268.

Cao, H., Li, Q., Li, M., Od, R., Wu, Z., Zhou, Q., Cao, B., Chen, B., Chen, Y., \& Wang, D. (2013). Osteoprotegerin/RANK/RANKL axis and atrial remodeling in mitral valvular patients with atrial fibrillation. Int J Cardiol, 166, 702-708.

Cao, H., Wang, J., Xi, L., Roe, O. D., Chen, Y., \& Wang, D. (2011). Dysregulated atrial gene expression of osteoprotegerin/receptor activator of nuclear factor-kappaB (RANK)/RANK ligand axis in the development and progression of atrial fibrillation. Circ J, 75, 2781-2788.

Cao, J. J. (2011). Effects of obesity on bone metabolism. J Orthop Surg Res, 6, 30.

Charles, J. F., Ermann, J., \& Aliprantis, A. O. (2015). The intestinal microbiome and skeletal fitness: Connecting bugs and bones. Clin Immunol, 159, 163-169.

Chisalita, S. I., \& Arnqvist, H. J. (2004). Insulin-like growth factor I receptors are more abundant than insulin receptors in human micro- and macrovascular endothelial cells. Am J Physiol Endocrinol Metab, 286, E896-901.

Choi, N. K., Solomon, D. H., Tsacogianis, T. N., Landon, J. E., Song, H. J., \& Kim, S. C. (2017). Comparative Safety and Effectiveness of Denosumab Versus Zoledronic Acid in Patients With Osteoporosis: A Cohort Study. J Bone Miner Res, 32, 611-617.

Chung, C. P., Solus, J. F., Oeser, A., Li, C., Raggi, P., Smith, J. R., \& Stein, C. M. (2015). A variant in the osteoprotegerin gene is associated with coronary atherosclerosis in patients with rheumatoid arthritis: results from a candidate gene study. Int J Mol Sci, 16, 3885-3894.

Cianciolo, G., Capelli, I., Angelini, M. L., Valentini, C., Baraldi, O., Scolari, M. P., \& Stefoni, S. (2014). Importance of vascular calcification in kidney transplant recipients. Am J Nephrol, 39, 418426.

Condliffe, R., Pickworth, J. A., Hopkinson, K., Walker, S. J., Hameed, A. G., Suntharaligam, J., Soon, E., Treacy, C., Pepke-Zaba, J., Francis, S. E., Crossman, D. C., Newman, C. M., Elliot, C. A., Morton, A. C., Morrell, N. W., Kiely, D. G., \& Lawrie, A. (2012). Serum osteoprotegerin is increased and predicts survival in idiopathic pulmonary arterial hypertension. Pulm Circ, 2, 21-27.

Corallini, F., Gonelli, A., D'Aurizio, F., di lasio, M. G., \& Vaccarezza, M. (2009). Mesenchymal stem cells-derived vascular smooth muscle cells release abundant levels of osteoprotegerin. Eur J Histochem, 53, 19-24.

Cosman, F., Crittenden, D. B., Adachi, J. D., Binkley, N., Czerwinski, E., Ferrari, S., Hofbauer, L. C., Lau, E., Lewiecki, E. M., Miyauchi, A., Zerbini, C. A., Milmont, C. E., Chen, L., Maddox, J., Meisner, P. D., Libanati, C., \& Grauer, A. (2016). Romosozumab Treatment in Postmenopausal Women with Osteoporosis. N Engl J Med, 375, 1532-1543.

Crisafulli, A., Micari, A., Altavilla, D., Saporito, F., Sardella, A., Passaniti, M., Raffa, S., D'Anneo, G., Luca, F., Mioni, C., Arrigo, F., \& Squadrito, F. (2005). Serum levels of osteoprotegerin and RANKL in patients with ST elevation acute myocardial infarction. Clin Sci (Lond), 109, 389-395.

Cross, S. S., Yang, Z., Brown, N. J., Balasubramanian, S. P., Evans, C. A., Woodward, J. K., NevilleWebbe, H. L., Lippitt, J. M., Reed, M. W., Coleman, R. E., \& Holen, I. (2006). Osteoprotegerin (OPG)--a potential new role in the regulation of endothelial cell phenotype and tumour angiogenesis? Int J Cancer, 118, 1901-1908.

Cummings, S. R., San Martin, J., McClung, M. R., Siris, E. S., Eastell, R., Reid, I. R., Delmas, P., Zoog, H. B., Austin, M., Wang, A., Kutilek, S., Adami, S., Zanchetta, J., Libanati, C., Siddhanti, S., Christiansen, C., \& Trial, F. (2009). Denosumab for prevention of fractures in postmenopausal women with osteoporosis. N Engl J Med, 361, 756-765. 
Cunha, D. A., Cito, M., Carlsson, P. O., Vanderwinden, J. M., Molkentin, J. D., Bugliani, M., Marchetti, P., Eizirik, D. L., \& Cnop, M. (2016). Thrombospondin 1 protects pancreatic beta-cells from lipotoxicity via the PERK-NRF2 pathway. Cell Death Differ, 23, 1995-2006.

Davenport, C., Ashley, D. T., O'Sullivan, E. P., McHenry, C. M., Agha, A., Thompson, C. J., O'Gorman, D. J., \& Smith, D. (2015). The Effects of Atorvastatin on Arterial Stiffness in Male Patients with Type 2 Diabetes. J Diabetes Res, 2015, 846807.

Deftereos, S., Giannopoulos, G., Kossyvakis, C., Kaoukis, A., Raisakis, K., Panagopoulou, V., Miliou, A., Theodorakis, A., Driva, M., Pyrgakis, V., Stefanadis, C., \& Cleman, M. W. (2012). Association of soluble tumour necrosis factor-related apoptosis-inducing ligand levels with coronary plaque burden and composition. Heart, 98, 214-218.

Demir, P., Erdenen, F., Aral, H., Emre, T., Kose, S., Altunoglu, E., Dolgun, A., Inal, B. B., \& Turkmen, A. (2016). Serum Osteoprotegerin Levels Related With Cardiovascular Risk Factors in Chronic Kidney Disease. J Clin Lab Anal, 30, 811-817.

Di Bartolo, B. A., Schoppet, M., Mattar, M. Z., Rachner, T. D., Shanahan, C. M., \& Kavurma, M. M. (2011). Calcium and osteoprotegerin regulate IGF1R expression to inhibit vascular calcification. Cardiovascular Research, 91, 537-545.

di Giuseppe, R., Biemann, R., Wirth, J., Menzel, J., Isermann, B., Stangl, G. I., Fritsche, A., Boeing, H., Schulze, M. B., \& Weikert, C. (2017). Plasma osteoprotegerin, its correlates, and risk of heart failure: a prospective cohort study. Eur J Epidemiol, 32, 113-123.

Dzeshka, M. S., Lip, G. Y., Snezhitskiy, V., \& Shantsila, E. (2015). Cardiac Fibrosis in Patients With Atrial Fibrillation: Mechanisms and Clinical Implications. J Am Coll Cardiol, 66, 943-959.

Ejtahed, H. S., Soroush, A. R., Angoorani, P., Larijani, B., \& Hasani-Ranjbar, S. (2016). Gut Microbiota as a Target in the Pathogenesis of Metabolic Disorders: A New Approach to Novel Therapeutic Agents. Horm Metab Res, 48, 349-358.

Estanislau, I. M., Terceiro, I. R., Lisboa, M. R., Teles Pde, B., Carvalho Rde, S., Martins, R. S., \& Moreira, M. M. (2015). Pleiotropic effects of statins on the treatment of chronic periodontitis--a systematic review. Br J Clin Pharmacol, 79, 877-885.

Forde, H., Harper, E., Davenport, C., Rochfort, K. D., Wallace, R., Murphy, R. P., Smith, D., \& Cummins, P. M. (2016). The beneficial pleiotropic effects of tumour necrosis factor-related apoptosisinducing ligand (TRAIL) within the vasculature: A review of the evidence. Atherosclerosis, 247, 87-96.

Frey, R. S., Ushio-Fukai, M., \& Malik, A. B. (2009). NADPH oxidase-dependent signaling in endothelial cells: role in physiology and pathophysiology. Antioxid Redox Signal, 11, 791-810.

Frioes, F., Laszczynska, O., Almeida, P. B., Silva, N., Guimaraes, J. T., Omland, T., Azevedo, A., \& Bettencourt, P. (2015). Prognostic Value of Osteoprotegerin in Acute Heart Failure. Can J Cardiol, 31, 1266-1271.

Fuernau, G., Zaehringer, S., Eitel, I., de Waha, S., Droppa, M., Desch, S., Schuler, G., Adams, V., \& Thiele, H. (2013). Osteoprotegerin in ST-elevation myocardial infarction: prognostic impact and association with markers of myocardial damage by magnetic resonance imaging. Int $J$ Cardiol, 167, 2134-2139.

Fulzele, K., \& Clemens, T. L. (2012). Novel functions for insulin in bone. Bone, 50, 452-456.

Gannage-Yared, M. H., Yaghi, C., Habre, B., Khalife, S., Noun, R., Germanos-Haddad, M., \& TrakSmayra, V. (2008). Osteoprotegerin in relation to body weight, lipid parameters insulin sensitivity, adipocytokines, and C-reactive protein in obese and non-obese young individuals: results from both cross-sectional and interventional study. Eur J Endocrinol, 158, 353-359.

Genre, F., Lopez-Mejias, R., Garcia-Bermudez, M., Castaneda, S., Gonzalez-Juanatey, C., Llorca, J., Corrales, A., Ubilla, B., Miranda-Filloy, J. A., Pina, T., Gomez-Vaquero, C., RodriguezRodriguez, L., Fernandez-Gutierrez, B., Balsa, A., Pascual-Salcedo, D., Lopez-Longo, F. J., Carreira, P., Blanco, R., Gonzalez-Alvaro, I., Martin, J., \& Gonzalez-Gay, M. A. (2014). Osteoprotegerin CGA haplotype protection against cerebrovascular complications in anti-CCP negative patients with rheumatoid arthritis. PLoS One, 9, e106823. 
Giachelli, C. M., Bae, N., Almeida, M., Denhardt, D. T., Alpers, C. E., \& Schwartz, S. M. (1993). Osteopontin is elevated during neointima formation in rat arteries and is a novel component of human atherosclerotic plaques. Journal of Clinical Investigation, 92, 1686-1696.

Gonzalez-Gay, M. A., Llorca, J., Palomino-Morales, R., Gomez-Acebo, I., Gonzalez-Juanatey, C., \& Martin, J. (2009). Influence of nitric oxide synthase gene polymorphisms on the risk of cardiovascular events in rheumatoid arthritis. Clin Exp Rheumatol, 27, 116-119.

Guo, C., Hu, F., Zhang, S., Wang, Y., \& Liu, H. (2013). Association between osteoprotegerin gene polymorphisms and cardiovascular disease in type 2 diabetic patients. Genet Mol Biol, 36, 177-182.

Hao, Y., Tsuruda, T., Sekita-Hatakeyama, Y., Kurogi, S., Kubo, K., Sakamoto, S., Nakamura, M., Udagawa, N., Sekimoto, T., Hatakeyama, K., Chosa, E., Asada, Y., \& Kitamura, K. (2016). Cardiac hypertrophy is exacerbated in aged mice lacking the osteoprotegerin gene. Cardiovascular Research, 110, 62-72.

Harper, E., Forde, H., Davenport, C., Rochfort, K. D., Smith, D., \& Cummins, P. M. (2016). Vascular calcification in type-2 diabetes and cardiovascular disease: Integrative roles for OPG, RANKL and TRAIL. Vascul Pharmacol, 82, 30-40.

Haxaire, C., Hay, E., \& Geoffroy, V. (2016). Runx2 Controls Bone Resorption through the DownRegulation of the Wnt Pathway in Osteoblasts. Am J Pathol, 186, 1598-1609.

Helas, S., Goettsch, C., Schoppet, M., Zeitz, U., Hempel, U., Morawietz, H., Kostenuik, P. J., Erben, R. G., \& Hofbauer, L. C. (2009). Inhibition of receptor activator of NF-kappaB ligand by denosumab attenuates vascular calcium deposition in mice. Am J Pathol, 175, 473-478.

Higashi, Y., Sukhanov, S., Anwar, A., Shai, S. Y., \& Delafontaine, P. (2010). IGF-1, oxidative stress and atheroprotection. Trends Endocrinol Metab, 21, 245-254.

Hofbauer, L. C., \& Schoppet, M. (2002). Osteoprotegerin gene polymorphism and the risk of osteoporosis and vascular disease. J Clin Endocrinol Metab, 87, 4078-4079.

Holecki, M., Zahorska-Markiewicz, B., Janowska, J., Nieszporek, T., Wojaczynska-Stanek, K., ZakGolab, A., \& Wiecek, A. (2007). The influence of weight loss on serum osteoprotegerin concentration in obese perimenopausal women. Obesity (Silver Spring), 15, 1925-1929.

Iwai, K., Koike, M., Ohshima, S., Miyatake, K., Uchiyama, Y., Saeki, Y., \& Ishii, M. (2007). RGS18 acts as a negative regulator of osteoclastogenesis by modulating the acid-sensing OGR1/NFAT signaling pathway. J Bone Miner Res, 22, 1612-1620.

Jalife, J. (2014). Mechanisms of persistent atrial fibrillation. Curr Opin Cardiol, 29, 20-27.

Johnson, R. C., Leopold, J. A., \& Loscalzo, J. (2006). Vascular calcification: pathobiological mechanisms and clinical implications. Circulation Research, 99, 1044-1059.

Joiner, D. M., Ke, J., Zhong, Z., Xu, H. E., \& Williams, B. O. (2013). LRP5 and LRP6 in development and disease. Trends Endocrinol Metab, 24, 31-39.

Jono, S., Otsuki, S., Higashikuni, Y., Shioi, A., Mori, K., Hara, K., Hashimoto, H., \& Ikari, Y. (2010). Serum osteoprotegerin levels and long-term prognosis in subjects with stable coronary artery disease. J Thromb Haemost, 8, 1170-1175.

Jono, S., Shioi, A., Ikari, Y., \& Nishizawa, Y. (2006). Vascular calcification in chronic kidney disease. J Bone Miner Metab, 24, 176-181.

Kanno, Y., Into, T., Lowenstein, C. J., \& Matsushita, K. (2008). Nitric oxide regulates vascular calcification by interfering with TGF- signalling. Cardiovascular Research, 77, 221-230.

Kiechl, S., Schett, G., Wenning, G., Redlich, K., Oberhollenzer, M., Mayr, A., Santer, P., Smolen, J., Poewe, W., \& Willeit, J. (2004). Osteoprotegerin is a risk factor for progressive atherosclerosis and cardiovascular disease. Circulation, 109, 2175-2180.

Kiechl, S., Werner, P., Knoflach, M., Furtner, M., Willeit, J., \& Schett, G. (2006). The osteoprotegerin/RANK/RANKL system: a bone key to vascular disease. Expert Rev Cardiovasc Ther, 4, 801-811.

Kim, K. J., Kim, J. Y., Baek, I. W., Kim, W. U., \& Cho, C. S. (2015). Elevated serum levels of syndecan-1 are associated with renal involvement in patients with systemic lupus erythematosus. $J$ Rheumatol, 42, 202-209. 
Knudsen, S. T., Foss, C. H., Poulsen, P. L., Andersen, N. H., Mogensen, C. E., \& Rasmussen, L. M. (2003). Increased plasma concentrations of osteoprotegerin in type 2 diabetic patients with microvascular complications. Eur J Endocrinol, 149, 39-42.

Koole, D., Hurks, R., Schoneveld, A., Vink, A., Golledge, J., Moran, C. S., de Kleijn, D. P., van Herwaarden, J. A., de Vries, J. P., Laman, J. D., Huizinga, R., Pasterkamp, G., \& Moll, F. L. (2012). Osteoprotegerin is associated with aneurysm diameter and proteolysis in abdominal aortic aneurysm disease. Arterioscler Thromb Vasc Biol, 32, 1497-1504.

Kramer, I., Halleux, C., Keller, H., Pegurri, M., Gooi, J. H., Weber, P. B., Feng, J. Q., Bonewald, L. F., \& Kneissel, M. (2010). Osteocyte Wnt/beta-catenin signaling is required for normal bone homeostasis. Mol Cell Biol, 30, 3071-3085.

Kranenburg, G., Bartstra, J. W., Weijmans, M., de Jong, P. A., Mali, W. P., Verhaar, H. J., Visseren, F. L., \& Spiering, W. (2016). Bisphosphonates for cardiovascular risk reduction: A systematic review and meta-analysis. Atherosclerosis, 252, 106-115.

Krishna, S. M., \& Golledge, J. (2013). The role of thrombospondin-1 in cardiovascular health and pathology. Int J Cardiol, 168, 692-706.

Kubota, T., Michigami, T., \& Ozono, K. (2009). Wnt signaling in bone metabolism. J Bone Miner Metab, 27, 265-271.

Kuroda, Y., \& Matsuo, K. (2012). Molecular mechanisms of triggering, amplifying and targeting RANK signaling in osteoclasts. World J Orthop, 3, 167-174.

Kusumbe, A. P., Ramasamy, S. K., \& Adams, R. H. (2014). Coupling of angiogenesis and osteogenesis by a specific vessel subtype in bone. Nature, 507, 323-328.

Kuzniewski, M., Fedak, D., Dumnicka, P., Stepien, E., Kusnierz-Cabala, B., Cwynar, M., \& Sulowicz, W. (2016). Osteoprotegerin and osteoprotegerin/TRAIL ratio are associated with cardiovascular dysfunction and mortality among patients with renal failure. Adv Med Sci, 61, 269-275.

Labovsky, V., Vallone, V. B., Martinez, L. M., Otaegui, J., \& Chasseing, N. A. (2012). Expression of osteoprotegerin, receptor activator of nuclear factor kappa-B ligand, tumor necrosis factorrelated apoptosis-inducing ligand, stromal cell-derived factor-1 and their receptors in epithelial metastatic breast cancer cell lines. Cancer Cell Int, 12, 29.

Lacey, D. L., Boyle, W. J., Simonet, W. S., Kostenuik, P. J., Dougall, W. C., Sullivan, J. K., San Martin, J., \& Dansey, R. (2012). Bench to bedside: elucidation of the OPG-RANK-RANKL pathway and the development of denosumab. Nat Rev Drug Discov, 11, 401-419.

Lawrie, A., Waterman, E., Southwood, M., Evans, D., Suntharalingam, J., Francis, S., Crossman, D., Croucher, P., Morrell, N., \& Newman, C. (2008). Evidence of a role for osteoprotegerin in the pathogenesis of pulmonary arterial hypertension. Am J Pathol, 172, 256-264.

Lee, J., Packard, R. R., \& Hsiai, T. K. (2015). Blood flow modulation of vascular dynamics. Curr Opin Lipidol, 26, 376-383.

Lerman, D. A., Prasad, S., \& Alotti, N. (2015). Calcific Aortic Valve Disease: Molecular Mechanisms and Therapeutic Approaches. Eur Cardiol, 10, 108-112.

Li, B., Lu, D., Chen, Y., Zhao, M., \& Zuo, L. (2016). Unfractionated Heparin Promotes Osteoclast Formation in Vitro by Inhibiting Osteoprotegerin Activity. Int J Mol Sci, 17.

Li, M., Yang, S., \& Xu, D. (2016). Heparan Sulfate Regulates the Structure and Function of Osteoprotegerin in Osteoclastogenesis. Journal of Biological Chemistry, 291, 24160-24171.

Li, V. S., Ng, S. S., Boersema, P. J., Low, T. Y., Karthaus, W. R., Gerlach, J. P., Mohammed, S., Heck, A. J., Maurice, M. M., Mahmoudi, T., \& Clevers, H. (2012). Wnt signaling through inhibition of beta-catenin degradation in an intact Axin1 complex. Cell, 149, 1245-1256.

Lin, M. E., Chen, T. M., Wallingford, M. C., Nguyen, N. B., Yamada, S., Sawangmake, C., Zhang, J., Speer, M. Y., \& Giachelli, C. M. (2016). Runx2 Deletion in Smooth muscle Cells Inhibits Vascular Osteochondrogenesis and Calcification but not Atherosclerotic Lesion Formation. Cardiovascular Research.

Lopez-Mejias, R., Castaneda, S., Gonzalez-Juanatey, C., Corrales, A., Ferraz-Amaro, I., Genre, F., Remuzgo-Martinez, S., Rodriguez-Rodriguez, L., Blanco, R., Llorca, J., Martin, J., \& Gonzalez- 
Gay, M. A. (2016). Cardiovascular risk assessment in patients with rheumatoid arthritis: The relevance of clinical, genetic and serological markers. Autoimmun Rev, 15, 1013-1030.

Lopez-Mejias, R., Ubilla, B., Genre, F., Corrales, A., Hernandez, J. L., Ferraz-Amaro, I., Tsang, L., Llorca, J., Blanco, R., Gonzalez-Juanatey, C., Gonzalez-Gay, M. A., \& Dessein, P. H. (2015). Osteoprotegerin concentrations relate independently to established cardiovascular disease in rheumatoid arthritis. J Rheumatol, 42, 39-45.

Luo, J., Yang, Z., Ma, Y., Yue, Z., Lin, H., Qu, G., Huang, J., Dai, W., Li, C., Zheng, C., Xu, L., Chen, H., Wang, J., Li, D., Siwko, S., Penninger, J. M., Ning, G., Xiao, J., \& Liu, M. (2016). LGR4 is a receptor for RANKL and negatively regulates osteoclast differentiation and bone resorption. Nat Med, 22, 539-546.

Maes, C., Goossens, S., Bartunkova, S., Drogat, B., Coenegrachts, L., Stockmans, I., Moermans, K., Nyabi, O., Haigh, K., Naessens, M., Haenebalcke, L., Tuckermann, J. P., Tjwa, M., Carmeliet, P., Mandic, V., David, J. P., Behrens, A., Nagy, A., Carmeliet, G., \& Haigh, J. J. (2010). Increased skeletal VEGF enhances beta-catenin activity and results in excessively ossified bones. EMBO J, 29, 424-441.

Mangan, S. H., Van Campenhout, A., Rush, C., \& Golledge, J. (2007). Osteoprotegerin upregulates endothelial cell adhesion molecule response to tumor necrosis factor-alpha associated with induction of angiopoietin-2. Cardiovascular Research, 76, 494-505.

Manolagas, S. C., O'Brien, C. A., \& Almeida, M. (2013). The role of estrogen and androgen receptors in bone health and disease. Nat Rev Endocrinol, 9, 699-712.

McGonigle, J. S., Giachelli, C. M., \& Scatena, M. (2009). Osteoprotegerin and RANKL differentially regulate angiogenesis and endothelial cell function. Angiogenesis, 12, 35-46.

Meluzin, J., \& Tomandl, J. (2015). Can biomarkers help to diagnose early heart failure with preserved ejection fraction? Dis Markers, 2015, 426045.

Mencke, R., Hillebrands, J. L., \& consortium, N. (2017). The role of the anti-ageing protein Klotho in vascular physiology and pathophysiology. Ageing Res Rev, 35, 124-146.

Messalli, E. M., Mainini, G., Scaffa, C., Cafiero, A., Salzillo, P. L., Ragucci, A., \& Cobellis, L. (2007). Raloxifene therapy interacts with serum osteoprotegerin in postmenopausal women. Maturitas, 56, 38-44.

Mezquita-Raya, P., de la Higuera, M., Garcia, D. F., Alonso, G., Ruiz-Requena, M. E., de Dios Luna, J., Escobar-Jimenez, F., \& Munoz-Torres, M. (2005). The contribution of serum osteoprotegerin to bone mass and vertebral fractures in postmenopausal women. Osteoporos Int, 16, 13681374.

Mimura, J., \& Itoh, K. (2015). Role of Nrf2 in the pathogenesis of atherosclerosis. Free Radical Biology \& Medicine, $88,221-232$.

Min, H., Morony, S., Sarosi, I., Dunstan, C. R., Capparelli, C., Scully, S., Van, G., Kaufman, S., Kostenuik, P. J., Lacey, D. L., Boyle, W. J., \& Simonet, W. S. (2000). Osteoprotegerin reverses osteoporosis by inhibiting endosteal osteoclasts and prevents vascular calcification by blocking a process resembling osteoclastogenesis. J Exp Med, 192, 463-474.

Moester, M. J., Papapoulos, S. E., Lowik, C. W., \& van Bezooijen, R. L. (2010). Sclerostin: current knowledge and future perspectives. Calcif Tissue Int, 87, 99-107.

Mogelvang, R., Haahr-Pedersen, S., Bjerre, M., Frystyk, J., Iversen, A., Galatius, S., Flyvbjerg, A., \& Jensen, J. S. (2013). Osteoprotegerin improves risk detection by traditional cardiovascular risk factors and hsCRP. Heart, 99, 106-110.

Montagnana, M., Lippi, G., Danese, E., \& Guidi, G. C. (2013). The role of osteoprotegerin in cardiovascular disease. Ann Med, 45, 254-264.

Montecucco, F., Steffens, S., \& Mach, F. (2007). The immune response is involved in atherosclerotic plaque calcification: could the RANKL/RANK/OPG system be a marker of plaque instability? Clin Dev Immunol, 2007, 75805.

Moran, C. S., McCann, M., Karan, M., Norman, P., Ketheesan, N., \& Golledge, J. (2005). Association of osteoprotegerin with human abdominal aortic aneurysm progression. Circulation, 111, 31193125. 
Morinaga, T., Nakagawa, N., Yasuda, H., Tsuda, E., \& Higashio, K. (1998). Cloning and characterization of the gene encoding human osteoprotegerin/osteoclastogenesis-inhibitory factor. European Journal of Biochemistr, 254, 685-691.

Morisawa, T., Nakagomi, A., Kohashi, K., Kosugi, M., Kusama, Y., Atarashi, H., \& Shimizu, W. (2015). Osteoprotegerin is Associated With Endothelial Function and Predicts Early Carotid Atherosclerosis in Patients With Coronary Artery Disease. Int Heart J, 56, 605-612.

Morony, S., Tintut, Y., Zhang, Z., Cattley, R. C., Van, G., Dwyer, D., Stolina, M., Kostenuik, P. J., \& Demer, L. L. (2008). Osteoprotegerin inhibits vascular calcification without affecting atherosclerosis in Idlr(-/-) mice. Circulation, 117, 411-420.

Mosheimer, B. A., Kaneider, N. C., Feistritzer, C., Djanani, A. M., Sturn, D. H., Patsch, J. R., \& Wiedermann, C. J. (2005). Syndecan-1 is involved in osteoprotegerin-induced chemotaxis in human peripheral blood monocytes. J Clin Endocrinol Metab, 90, 2964-2971.

Nagy, E. E., Varga-Fekete, T., Puskas, A., Kelemen, P., Brassai, Z., Szekeres-Csiki, K., Gombos, T., Csanyi, M. C., \& Harsfalvi, J. (2016). High circulating osteoprotegerin levels are associated with non-zero blood groups. BMC Cardiovasc Disord, 16, 106.

Nakahara, T., Dweck, M. R., Narula, N., Pisapia, D., Narula, J., \& Strauss, H. W. (2017). Coronary Artery Calcification: From Mechanism to Molecular Imaging. JACC Cardiovasc Imaging, 10, 582-593.

Nakahara, T., Kawai-Kowase, K., Matsui, H., Sunaga, H., Utsugi, T., Iso, T., Arai, M., Tomono, S., \& Kurabayashi, M. (2016). Fibroblast growth factor 23 inhibits osteoblastic gene expression and induces osteoprotegerin in vascular smooth muscle cells. Atherosclerosis, 253, 102-110.

Naot, D., Choi, A., Musson, D. S., Simsek Kiper, P. O., Utine, G. E., Boduroglu, K., Peacock, M., DiMeglio, L. A., \& Cundy, T. (2014). Novel homozygous mutations in the osteoprotegerin gene TNFRSF11B in two unrelated patients with juvenile Paget's disease. Bone, 68, 6-10.

Neville-Webbe, H. L., Cross, N. A., Eaton, C. L., Nyambo, R., Evans, C. A., Coleman, R. E., \& Holen, I. (2004). Osteoprotegerin (OPG) produced by bone marrow stromal cells protects breast cancer cells from TRAIL-induced apoptosis. Breast Cancer Res Treat, 86, 269-279.

Nicoll, R., Zhao, Y., Ibrahimi, P., Olivecrona, G., \& Henein, M. (2016). Diabetes and Hypertension Consistently Predict the Presence and Extent of Coronary Artery Calcification in Symptomatic Patients: A Systematic Review and Meta-Analysis. Int J Mol Sci, 17.

Niessner, A., Hohensinner, P. J., Rychli, K., Neuhold, S., Zorn, G., Richter, B., Hulsmann, M., Berger, R., Mortl, D., Huber, K., Wojta, J., \& Pacher, R. (2009). Prognostic value of apoptosis markers in advanced heart failure patients. Eur Heart J, 30, 789-796.

Nybo, M., \& Rasmussen, L. M. (2008). Osteoprotegerin released from the vascular wall by heparin mainly derives from vascular smooth muscle cells. Atherosclerosis, 201, 33-35.

Oh, E. S., Rhee, E. J., Oh, K. W., Lee, W. Y., Baek, K. H., Yoon, K. H., Kang, M. I., Yun, E. J., Park, C. Y., Choi, M. G., Yoo, H. J., \& Park, S. W. (2005). Circulating osteoprotegerin levels are associated with age, waist-to-hip ratio, serum total cholesterol, and low-density lipoprotein cholesterol levels in healthy Korean women. Metabolism, 54, 49-54.

Omland, T., Ueland, T., Jansson, A. M., Persson, A., Karlsson, T., Smith, C., Herlitz, J., Aukrust, P., Hartford, M., \& Caidahl, K. (2008). Circulating osteoprotegerin levels and long-term prognosis in patients with acute coronary syndromes. J Am Coll Cardiol, 51, 627-633.

Orita, Y., Yamamoto, H., Kohno, N., Sugihara, M., Honda, H., Kawamata, S., Mito, S., Soe, N. N., \& Yoshizumi, M. (2007). Role of osteoprotegerin in arterial calcification: development of new animal model. Arterioscler Thromb Vasc Biol, 27, 2058-2064.

Osako, M. K., Nakagami, H., Koibuchi, N., Shimizu, H., Nakagami, F., Koriyama, H., Shimamura, M., Miyake, T., Rakugi, H., \& Morishita, R. (2010). Estrogen inhibits vascular calcification via vascular RANKL system: common mechanism of osteoporosis and vascular calcification. Circulation Research, 107, 466-475.

Oudot, A., Martin, C., Busseuil, D., Vergely, C., Demaison, L., \& Rochette, L. (2006). NADPH oxidases are in part responsible for increased cardiovascular superoxide production during aging. Free Radical Biology \& Medicine, 40, 2214-2222. 
Pan, Y., Liang, H., Liu, H., Li, D., Chen, X., Li, L., Zhang, C. Y., \& Zen, K. (2014). Platelet-secreted microRNA-223 promotes endothelial cell apoptosis induced by advanced glycation end products via targeting the insulin-like growth factor 1 receptor. J Immunol, 192, 437-446.

Panizo, S., Cardus, A., Encinas, M., Parisi, E., Valcheva, P., Lopez-Ongil, S., Coll, B., Fernandez, E., \& Valdivielso, J. M. (2009). RANKL increases vascular smooth muscle cell calcification through a RANK-BMP4-dependent pathway. Circulation Research, 104, 1041-1048.

Perez de Ciriza, C., Lawrie, A., \& Varo, N. (2015). Osteoprotegerin in Cardiometabolic Disorders. Int J Endocrinol, 2015, 564934.

Perez de Ciriza, C., Moreno, M., Restituto, P., Bastarrika, G., Simon, I., Colina, I., \& Varo, N. (2014). Circulating osteoprotegerin is increased in the metabolic syndrome and associates with subclinical atherosclerosis and coronary arterial calcification. Clin Biochem, 47, 272-278.

Persy, V., \& D'Haese, P. (2009). Vascular calcification and bone disease: the calcification paradox. Trends Mol Med, 15, 405-416.

Pietschmann, P., Mechtcheriakova, D., Meshcheryakova, A., Foger-Samwald, U., \& Ellinger, I. (2016). Immunology of Osteoporosis: A Mini-Review. Gerontology, 62, 128-137.

Pimanda, J. E., Annis, D. S., Raftery, M., Mosher, D. F., Chesterman, C. N., \& Hogg, P. J. (2002). The von Willebrand factor-reducing activity of thrombospondin-1 is located in the calciumbinding/C-terminal sequence and requires a free thiol at position 974. Blood, 100, 28322838.

Pober, J. S., \& Tellides, G. (2012). Participation of blood vessel cells in human adaptive immune responses. Trends Immunol, 33, 49-57.

Pritzker, L. B., Scatena, M., \& Giachelli, C. M. (2004). The role of osteoprotegerin and tumor necrosis factor-related apoptosis-inducing ligand in human microvascular endothelial cell survival. Mol Biol Cell, 15, 2834-2841.

Quercioli, A., Mach, F., Bertolotto, M., Lenglet, S., Vuilleumier, N., Galan, K., Pagano, S., Braunersreuther, V., Pelli, G., Pistoia, V., Bianchi, G., Cittadini, G., Viviani, G. L., Pende, A., Roux-Lombard, P., Thomas, A., Staub, C., Ratib, O., Dallegri, F., Schindler, T. H., \& Montecucco, F. (2012). Receptor activator of NF- kappaB ligand (RANKL) increases the release of neutrophil products associated with coronary vulnerability. Thromb Haemost, 107, 124-139.

Ramasamy, S. K., Kusumbe, A. P., Wang, L., \& Adams, R. H. (2014). Endothelial Notch activity promotes angiogenesis and osteogenesis in bone. Nature, 507, 376-380.

Raposo, G., \& Stoorvogel, W. (2013). Extracellular vesicles: exosomes, microvesicles, and friends. J Cell Biol, 200, 373-383.

Rasmussen, L. M., \& Ledet, T. (2005). Osteoprotegerin and diabetic macroangiopathy. Horm Metab Res, 37 Suppl 1, 90-94.

Rasmussen, L. M., Tarnow, L., Hansen, T. K., Parving, H. H., \& Flyvbjerg, A. (2006). Plasma osteoprotegerin levels are associated with glycaemic status, systolic blood pressure, kidney function and cardiovascular morbidity in type 1 diabetic patients. Eur J Endocrinol, 154, 7581.

Rattazzi, M., Faggin, E., Buso, R., Di Virgilio, R., Puato, M., Plebani, M., Zaninotto, M., Palmosi, T., Bertacco, E., Fadini, G. P., \& Pauletto, P. (2016). Atorvastatin Reduces Circulating Osteoprogenitor Cells and T-Cell RANKL Expression in Osteoporotic Women: Implications for the Bone-Vascular Axis. Cardiovasc Ther, 34, 13-20.

Reinhard, H., Lajer, M., Gall, M. A., Tarnow, L., Parving, H. H., Rasmussen, L. M., \& Rossing, P. (2010). Osteoprotegerin and mortality in type 2 diabetic patients. Diabetes Care, 33, 2561-2566.

Rewiuk, K., \& Grodzicki, T. (2015). Osteoprotegerin and TRAIL in Acute Onset of Atrial Fibrillation. Biomed Res Int, 2015, 259843.

Riegel, A., Maurer, T., Prior, B., Stegmaier, S., Heppert, V., Wagner, C., \& Hansch, G. M. (2012). Human polymorphonuclear neutrophils express RANK and are activated by its ligand, RANKL. Eur J Immunol, 42, 975-981. 
Rochette, L., Lorin, J., Zeller, M., Guilland, J. C., Lorgis, L., Cottin, Y., \& Vergely, C. (2013). Nitric oxide synthase inhibition and oxidative stress in cardiovascular diseases: possible therapeutic targets? Pharmacol Ther, 140, 239-257.

Rochette, L., Zeller, M., Cottin, Y., \& Vergely, C. (2014). Diabetes, oxidative stress and therapeutic strategies. Biochim Biophys Acta, 1840, 2709-2729.

Roth, G. A., Huffman, M. D., Moran, A. E., Feigin, V., Mensah, G. A., Naghavi, M., \& Murray, C. J. (2015). Global and regional patterns in cardiovascular mortality from 1990 to 2013. Circulation, 132, 1667-1678.

Rucci, N., Capulli, M., Piperni, S. G., Cappariello, A., Lau, P., Frings-Meuthen, P., Heer, M., \& Teti, A. (2015). Lipocalin 2: a new mechanoresponding gene regulating bone homeostasis. J Bone Miner Res, 30, 357-368.

Sage, A. P., Tintut, Y., \& Demer, L. L. (2010). Regulatory mechanisms in vascular calcification. Nat Rev Cardiol, 7, 528-536.

Sandberg, W. J., Yndestad, A., Oie, E., Smith, C., Ueland, T., Ovchinnikova, O., Robertson, A. K., Muller, F., Semb, A. G., Scholz, H., Andreassen, A. K., Gullestad, L., Damas, J. K., Froland, S. S., Hansson, G. K., Halvorsen, B., \& Aukrust, P. (2006). Enhanced T-cell expression of RANK ligand in acute coronary syndrome: possible role in plaque destabilization. Arterioscler Thromb Vasc Biol, 26, 857-863.

Schnabel, R. B., Larson, M. G., Yamamoto, J. F., Kathiresan, S., Rong, J., Levy, D., Keaney, J. F., Jr., Wang, T. J., Vasan, R. S., \& Benjamin, E. J. (2009). Relation of multiple inflammatory biomarkers to incident atrial fibrillation. Am J Cardiol, 104, 92-96.

Schneeweis, L. A., Willard, D., \& Milla, M. E. (2005). Functional dissection of osteoprotegerin and its interaction with receptor activator of NF-kappaB ligand. Journal of Biological Chemistry, 280, 41155-41164.

Schoppet, M., Al-Fakhri, N., Franke, F. E., Katz, N., Barth, P. J., Maisch, B., Preissner, K. T., \& Hofbauer, L. C. (2004). Localization of osteoprotegerin, tumor necrosis factor-related apoptosisinducing ligand, and receptor activator of nuclear factor-kappaB ligand in Monckeberg's sclerosis and atherosclerosis. J Clin Endocrinol Metab, 89, 4104-4112.

Schoppet, M., Henser, S., Ruppert, V., Stubig, T., Al-Fakhri, N., Maisch, B., \& Hofbauer, L. C. (2007). Osteoprotegerin expression in dendritic cells increases with maturation and is NF-kappaBdependent. J Cell Biochem, 100, 1430-1439.

Schoppet, M., Sattler, A. M., Schaefer, J. R., Herzum, M., Maisch, B., \& Hofbauer, L. C. (2003). Increased osteoprotegerin serum levels in men with coronary artery disease. J Clin Endocrinol Metab, 88, 1024-1028.

Schurgers, L. J., Cranenburg, E. C., \& Vermeer, C. (2008). Matrix Gla-protein: the calcification inhibitor in need of vitamin K. Thromb Haemost, 100, 593-603.

Schweighofer, N., Aigelsreiter, A., Trummer, O., Graf-Rechberger, M., Hacker, N., Kniepeiss, D., Wagner, D., Stiegler, P., Trummer, C., Pieber, T., Obermayer-Pietsch, B., \& Muller, H. (2016). Direct comparison of regulators of calcification between bone and vessels in humans. Bone, 88, 31-38.

Secchiero, P., Corallini, F., Rimondi, E., Chiaruttini, C., di lasio, M. G., Rustighi, A., Del Sal, G., \& Zauli, G. (2008). Activation of the p53 pathway down-regulates the osteoprotegerin expression and release by vascular endothelial cells. Blood, 111, 1287-1294.

Shanahan, C. M. (2013). Mechanisms of vascular calcification in CKD-evidence for premature ageing? Nat Rev Nephrol, 9, 661-670.

Shetelig, C., Limalanathan, S., Eritsland, J., Hoffmann, P., Seljeflot, I., Gran, J. M., Aukrust, P., Ueland, T., \& Andersen, G. O. (2017). Osteoprotegerin levels in ST-elevation myocardial infarction: Temporal profile and association with myocardial injury and left ventricular function. PLOS One, 12, e0173034.

Shi, G. X., Mao, W. W., Zheng, X. F., \& Jiang, L. S. (2016). The role of R-spondins and their receptors in bone metabolism. Prog Biophys Mol Biol, 122, 93-100. 
Shioi, A., Katagi, M., Okuno, Y., Mori, K., Jono, S., Koyama, H., \& Nishizawa, Y. (2002). Induction of bone-type alkaline phosphatase in human vascular smooth muscle cells: roles of tumor necrosis factor-alpha and oncostatin M derived from macrophages. Circulation Research, 91, 9-16.

Simonet, W. S., Lacey, D. L., Dunstan, C. R., Kelley, M., Chang, M. S., Luthy, R., Nguyen, H. Q., Wooden, S., Bennett, L., Boone, T., Shimamoto, G., DeRose, M., Elliott, R., Colombero, A., Tan, H. L., Trail, G., Sullivan, J., Davy, E., Bucay, N., Renshaw-Gegg, L., Hughes, T. M., Hill, D., Pattison, W., Campbell, P., Sander, S., Van, G., Tarpley, J., Derby, P., Lee, R., \& Boyle, W. J. (1997). Osteoprotegerin: a novel secreted protein involved in the regulation of bone density. Cell, 89, 309-319.

Sims, N. A., \& Martin, T. J. (2014). Coupling the activities of bone formation and resorption: a multitude of signals within the basic multicellular unit. Bonekey Rep, 3, 481.

Sims, N. A., \& Martin, T. J. (2015). Coupling Signals between the Osteoclast and Osteoblast: How are Messages Transmitted between These Temporary Visitors to the Bone Surface? Front Endocrinol (Lausanne), 6, 41.

Singh, S., Grabner, A., Yanucil, C., Schramm, K., Czaya, B., Krick, S., Czaja, M. J., Bartz, R., Abraham, R., Di Marco, G. S., Brand, M., Wolf, M., \& Faul, C. (2016). Fibroblast growth factor 23 directly targets hepatocytes to promote inflammation in chronic kidney disease. Kidney Int, 90, 985996.

Songia, P., Branchetti, E., Parolari, A., Myasoedova, V., Ferrari, G., Alamanni, F., Tremoli, E., \& Poggio, P. (2016). Mitral valve endothelial cells secrete osteoprotegerin during endothelial mesenchymal transition. Journal of Molecular \& Cellular Cardiology, 98, 48-57.

Soufi, M., Schoppet, M., Sattler, A. M., Herzum, M., Maisch, B., Hofbauer, L. C., \& Schaefer, J. R. (2004). Osteoprotegerin gene polymorphisms in men with coronary artery disease. J Clin Endocrinol Metab, 89, 3764-3768.

Soysal-Atile, N., Guldiken, S., Sipahi, T., Yukcu, F., Ekiz-Bilir, B., Huseyin, S., \& Tugrul, A. (2015). Relationship Between an Osteoprotegerin Gene Polymorphism and Diabetic Vascular Complications. Clin Lab, 61, 595-601.

Tang, P., Xiong, Q., Ge, W., \& Zhang, L. (2014). The role of microRNAs in osteoclasts and osteoporosis. RNA Biol, 11, 1355-1363.

Tarantino, U., Celi, M., Feola, M., Liuni, F. M., Resmini, G., \& Iolascon, G. (2013). A new antiresorptive approach to the treatment of fragility fractures: long-term efficacy and safety of denosumab. Aging Clin Exp Res, 25 Suppl 1, S65-69.

Tella, S. H., \& Gallagher, J. C. (2014). Prevention and treatment of postmenopausal osteoporosis. J Steroid Biochem Mol Biol, 142, 155-170.

Terekeci, H. M., Senol, M. G., Top, C., Sahan, B., Celik, S., Sayan, O., Kucukardali, Y., Ipcioglu, O., Cagiltay, E., Oktenli, C., \& Ozata, M. (2009). Plasma osteoprotegerin concentrations in type 2 diabetic patients and its association with neuropathy. Exp Clin Endocrinol Diabetes, 117, 119123.

Theoleyre, S., Kwan Tat, S., Vusio, P., Blanchard, F., Gallagher, J., Ricard-Blum, S., Fortun, Y., Padrines, M., Redini, F., \& Heymann, D. (2006). Characterization of osteoprotegerin binding to glycosaminoglycans by surface plasmon resonance: role in the interactions with receptor activator of nuclear factor kappaB ligand (RANKL) and RANK. Biochem Biophys Res Commun, $347,460-467$.

Theoleyre, S., Wittrant, Y., Tat, S. K., Fortun, Y., Redini, F., \& Heymann, D. (2004). The molecular triad OPG/RANK/RANKL: involvement in the orchestration of pathophysiological bone remodeling. Cytokine Growth Factor Rev, 15, 457-475.

Toffoli, B., Bernardi, S., Candido, R., Zacchigna, S., Fabris, B., \& Secchiero, P. (2012). TRAIL shows potential cardioprotective activity. Invest New Drugs, 30, 1257-1260.

Toffoli, B., Pickering, R. J., Tsorotes, D., Wang, B., Bernardi, S., Kantharidis, P., Fabris, B., Zauli, G., Secchiero, P., \& Thomas, M. C. (2011). Osteoprotegerin promotes vascular fibrosis via a TGFbeta1 autocrine loop. Atherosclerosis, 218, 61-68. 
Tomlinson, R. E., \& Silva, M. J. (2013). Skeletal Blood Flow in Bone Repair and Maintenance. Bone Res, 1, 311-322.

Troncoso, R., Ibarra, C., Vicencio, J. M., Jaimovich, E., \& Lavandero, S. (2014). New insights into IGF-1 signaling in the heart. Trends Endocrinol Metab, 25, 128-137.

Tsioufis, C., Aggelis, A., Dimitriadis, K., Thomopoulos, C., Kasiakogias, A., Tzamou, V., Kyvelou, S. M., Mikhailidis, D. P., Papademetriou, V., \& Stefanadis, C. (2011). Relationships of osteoprotegerin with albuminuria and asymmetric dimethylarginine in essential hypertension: integrating vascular dysfunction. Expert Opin Ther Targets, 15, 1347-1353.

Ueland, T., Yndestad, A., Oie, E., Florholmen, G., Halvorsen, B., Froland, S. S., Simonsen, S., Christensen, G., Gullestad, L., \& Aukrust, P. (2005). Dysregulated osteoprotegerin/RANK ligand/RANK axis in clinical and experimental heart failure. Circulation, 111, 2461-2468.

Uemura, H., Yasui, T., Miyatani, Y., Yamada, M., Hiyoshi, M., Arisawa, K., \& Irahara, M. (2008). Circulating osteoprotegerin is associated with age and systolic blood pressure, but not with lipid profile or fasting glucose, in postmenopausal women. Menopause, 15, 180-184.

Ugur-Altun, B., Altun, A., Gerenli, M., \& Tugrul, A. (2005). The relationship between insulin resistance assessed by HOMA-IR and serum osteoprotegerin levels in obesity. Diabetes Res Clin Pract, 68, 217-222.

van't Hof, R. J., \& Ralston, S. H. (2001). Nitric oxide and bone. Immunology, 103, 255-261.

Van Campenhout, A., \& Golledge, J. (2009). Osteoprotegerin, vascular calcification and atherosclerosis. Atherosclerosis, 204, 321-329.

Vassalle, C., \& Mazzone, A. (2016). Bone loss and vascular calcification: A bi-directional interplay? Vascul Pharmacol, 86, 77-86.

Veeriah, V., Zanniti, A., Paone, R., Chatterjee, S., Rucci, N., Teti, A., \& Capulli, M. (2016). Interleukin1beta, lipocalin 2 and nitric oxide synthase 2 are mechano-responsive mediators of mouse and human endothelial cell-osteoblast crosstalk. Sci Rep, 6, 29880.

Venuraju, S. M., Yerramasu, A., Corder, R., \& Lahiri, A. (2010). Osteoprotegerin as a predictor of coronary artery disease and cardiovascular mortality and morbidity. J Am Coll Cardiol, 55, 2049-2061.

Vidal, C., Formosa, R., \& Xuereb-Anastasi, A. (2011). Functional polymorphisms within the TNFRSF11B (osteoprotegerin) gene increase the risk for low bone mineral density. J Mol Endocrinol, 47, 327-333.

Viereck, V., Grundker, C., Blaschke, S., Frosch, K. H., Schoppet, M., Emons, G., \& Hofbauer, L. C. (2005). Atorvastatin stimulates the production of osteoprotegerin by human osteoblasts. J Cell Biochem, 96, 1244-1253.

Walsh, M. C., \& Choi, Y. (2014). Biology of the RANKL-RANK-OPG System in Immunity, Bone, and Beyond. Front Immunol, 5, 511.

Wang, Y., Nishida, S., Elalieh, H. Z., Long, R. K., Halloran, B. P., \& Bikle, D. D. (2006). Role of IGF-I signaling in regulating osteoclastogenesis. J Bone Miner Res, 21, 1350-1358.

Weiss, R. M., Lund, D. D., Chu, Y., Brooks, R. M., Zimmerman, K. A., El Accaoui, R., Davis, M. K., Hajj, G. P., Zimmerman, M. B., \& Heistad, D. D. (2013). Osteoprotegerin inhibits aortic valve calcification and preserves valve function in hypercholesterolemic mice. PLoS One, 8, e65201.

Weitzmann, M. N., \& Ofotokun, I. (2016). Physiological and pathophysiological bone turnover - role of the immune system. Nat Rev Endocrinol, 12, 518-532.

Wilson, M. E., \& Westberry, J. M. (2009). Regulation of oestrogen receptor gene expression: new insights and novel mechanisms. J Neuroendocrinol, 21, 238-242.

Wright, H. L., McCarthy, H. S., Middleton, J., \& Marshall, M. J. (2009). RANK, RANKL and osteoprotegerin in bone biology and disease. Curr Rev Musculoskelet Med, 2, 56-64.

Writing Group, M., Mozaffarian, D., Benjamin, E. J., Go, A. S., Arnett, D. K., Blaha, M. J., Cushman, M., Das, S. R., de Ferranti, S., Despres, J. P., Fullerton, H. J., Howard, V. J., Huffman, M. D., Isasi, C. R., Jimenez, M. C., Judd, S. E., Kissela, B. M., Lichtman, J. H., Lisabeth, L. D., Liu, S., Mackey, R. H., Magid, D. J., McGuire, D. K., Mohler, E. R., 3rd, Moy, C. S., Muntner, P., Mussolino, M. E., Nasir, K., Neumar, R. W., Nichol, G., Palaniappan, L., Pandey, D. K., Reeves, M. J., Rodriguez, 
C. J., Rosamond, W., Sorlie, P. D., Stein, J., Towfighi, A., Turan, T. N., Virani, S. S., Woo, D., Yeh, R. W., Turner, M. B., American Heart Association Statistics, C., \& Stroke Statistics, S. (2016). Executive Summary: Heart Disease and Stroke Statistics--2016 Update: A Report From the American Heart Association. Circulation, 133, 447-454.

Wu, G., Li, H., Zhou, M., Fang, Q., Bao, Y., Xu, A., \& Jia, W. (2014). Mechanism and clinical evidence of lipocalin-2 and adipocyte fatty acid-binding protein linking obesity and atherosclerosis. Diabetes Metab Res Rev, 30, 447-456.

Xie, P. (2013). TRAF molecules in cell signaling and in human diseases. J Mol Signal, 8, 7.

Yamaguchi, K., Kinosaki, M., Goto, M., Kobayashi, F., Tsuda, E., Morinaga, T., \& Higashio, K. (1998). Characterization of structural domains of human osteoclastogenesis inhibitory factor. Journal of Biological Chemistry, 273, 5117-5123.

Yan, J., Herzog, J. W., Tsang, K., Brennan, C. A., Bower, M. A., Garrett, W. S., Sartor, B. R., Aliprantis, A. O., \& Charles, J. F. (2016). Gut microbiota induce IGF-1 and promote bone formation and growth. Proc Natl Acad Sci U S A, 113, E7554-E7563.

Yao, Y., Wang, G., Wang, Z., Wang, C., Zhang, H., \& Liu, C. (2011). Synergistic enhancement of new bone formation by recombinant human bone morphogenetic protein-2 and osteoprotegerin in trans-sutural distraction osteogenesis: a pilot study in dogs. J Oral Maxillofac Surg, 69, e446-455.

Zannettino, A. C., Holding, C. A., Diamond, P., Atkins, G. J., Kostakis, P., Farrugia, A., Gamble, J., To, L. B., Findlay, D. M., \& Haynes, D. R. (2005). Osteoprotegerin (OPG) is localized to the WeibelPalade bodies of human vascular endothelial cells and is physically associated with von Willebrand factor. J Cell Physiol, 204, 714-723.

Zauli, G., Corallini, F., Bossi, F., Fischetti, F., Durigutto, P., Celeghini, C., Tedesco, F., \& Secchiero, P. (2007). Osteoprotegerin increases leukocyte adhesion to endothelial cells both in vitro and in vivo. Blood, 110, 536-543.

Zhang, H., Feng, L., Wan, Q., Hong, Y., Li, Y., Cheng, G., \& Han, X. (2015). Osteoprotegerin is associated with depletion of circulating endothelial progenitor cells and elevation in pulmonary arterial pressure in patients with systolic heart failure. Acta Cardiol, 70, 435-441.

Zhao, H. Y., Liu, J. M., Ning, G., Zhao, Y. J., Zhang, L. Z., Sun, L. H., Xu, M. Y., Uitterlinden, A. G., \& Chen, J. L. (2005). The influence of Lys3Asn polymorphism in the osteoprotegerin gene on bone mineral density in Chinese postmenopausal women. Osteoporos Int, 16, 1519-1524.

Ziegler, S., Kudlacek, S., Luger, A., \& Minar, E. (2005). Osteoprotegerin plasma concentrations correlate with severity of peripheral artery disease. Atherosclerosis, 182, 175-180. 


\section{Figure Legends}

FIGURE 1: Summary of the interactions between various tissues: adipose tissue, bone, vessel and kidney mediated by osteoprotegerin (OPG), FGF-23, soluble Klotho, VEGF, and oxidative stress, nitric oxide (NO), superoxide and iron.

Lipocalin-2 (LCN2) is an adipokine with specific lipid-binding activity and released from various cells during inflammation. It regulates bone homeostasis. Nitric oxide (NO) produced by NOS-2 in osteocytes and by the endothelium of the vessels integrated in bone is an important regulator of bone response to mechanical stress. Vascular endothelial growth factor (VEGF), beta-catenin, and hypoxiainducible factors (HIFs) are implicated in osteogenesis and angiogenesis. The major sources of ROS in ECs are enzymes such as NADPH oxidases (NOX) and the mitochondria. Klotho is a protein highly expressed in the kidney. Membrane Klotho protein acts as co-receptor for fibroblast growth factor23 (FGF-23). Klotho interacts with fibroblast growth factor receptors (FGFR-1) to form a high-affinity for FGF-23. Proteins exist consisting of two extracellular $\beta$-glucosidase-like domains (KL1 and KL2). The kidneys produce calcitriol (1,25- dihydroxycholecalciferol ): the hormonally active metabolite of vitamin $D$. The effects of calcitriol are mediated by its interaction with the calcitriol receptor (vitamin $D$ receptor: VDR). The transcription factor, early growth response 1 (EGR-1) plays a pivotal role in calcitriol metabolism, and its expression is regulated by the functions of EGR-1 and FGFR-1

FIGURE 2: Critical role of OPG/RANK/RANKL axis in the pathogenesis of vascular calcification. In the vasculature, RANKL-RANK-OPG signaling can be stimulated by various factors including inflammation, and reactive oxygen species (ROS). RANKL binds to the RANK receptor and activates the transcription factor nuclear factor KB (NF-KB). In presence of proinflammatory cytokines, the expression of endothelial cell (EC) adhesion molecules is increased, and is associated with the transmigration of lymphocytes and monocytes into the vessel wall. Fibroblast growth factor 23 (FGF-23) mediates the inhibition of osteogenic differentiation of vascular smooth muscle cells (VSMC) and the induction of OPG gene expression in the cells. The production of osteoprotegerin (OPG) in VSMCs and ECs is enhanced by inflammatory cytokines. OPG operates as a decoy receptor for RANKL and prevents RANK signaling and deposition of a mineralized matrix. OPG inhibits osteoclastogenesis. RANKL significantly increases the activity of matrix metalloprotease (MMP) in VSMCs. OPG neutralizes the effect of RANKL on the induction of MMP activity in VSMCs by inhibiting its binding to RANK. Inflammation and oxidative stress are two interacted factors that induced vascular calcification; driving the transition from VSMC to osteoblast phenotype. The differentiation of monocytes to osteoclast like cell is mediated by the monocyte chemotactic protein-1 (MCP-1), which involves production of ROS.

FIGURE 3: Molecular structure of osteoprotegerin.

Osteoprotegerin (OPG) is composed of 401 amino acid residues of which 21 are a signal peptide which is cleaved, generating a mature form of 380 amino acids. The N-terminal part of OPG is a cysteine-rich domain important for dimerization whereas the C-terminal contain a death domain and a domain for heparin binding. Circulating measurable OPG exists either as a free monomer of $60 \mathrm{kD}$ and a disulfide bond-linked homodimer form of $120 \mathrm{kD}$, or as OPG bound to its ligands, namely RANK Ligand (RANKL). OPG consists of 7 structural domains, of which the amino-terminal cysteine rich domains 1 to 4 (D1-D4) are necessary for binding to RANKL. The carboxy-terminal portion of the protein contains two regions (D5 and D6). In domain 7 (D7) at position 400 exists an unpaired cysteine residue implicated in disulfide bond formation and dimerization. RANKL binds to RANK on target cells, 
which triggers activation of nuclear factor $\mathrm{KB}(\mathrm{NF}-\mathrm{KB})$, resulting in its translocation to the nucleus. RANK is a transmembrane protein that is expressed on osteoclasts.

FIGURE 4: Schema illustrating the role of osteoblasts and osteoclasts in maintaining an appropriate bone remodeling balance.

Bone repairing/remodeling is dependent of a balance between the activities of osteoblasts and osteoclasts and its disturbance is associated with bone disorders including osteoporosis. The RANKL/RANK interaction stimulates differentiation of the osteoclasts. Osteoprotegerin (OPG) binds to RANKL and prevents the RANKL/RANK interaction. OPG also acts as a receptor for Tumor Necrosis Factor-Related Apoptosis Inducing Ligand (TRAIL). TRAIL activates caspases upon binding to its receptors TRAIL-R5. In the mechanisms of bone remodeling several key proteins, are implicated such as the tandem: Wnt/ low-density lipoprotein-related receptor: LRP 5,6/ $\beta$-catenin. Wnt promotes the differentiation of precursor cells into mature osteoblasts through the $\beta$-catenin-dependent pathway. Runt-related transcription factor-2 (RUNX2) and alkaline phosphatase (ALP) are initiators of bone mineralization. Leucine-rich repeats containing G-protein-coupled receptors (LGR-4) are receptors of R-spondin (RSPO) implicated in the mobilization of calcium. Sclerostin is an endogenous protein that inhibits osteoblast differentiation by binding to the LRP receptors.

Figure 5: Summary of the relationship between the OPG/RANKL system, the bone-vascular axis, and factors contributing to cardiometabolic risk.

Risk factors for cardiometabolic diseases are classified as non-modifiable (age, race, gender, gene and some endocrine disorders) and modifiable (traditional). The role of inflammation in cardiometabolic disorders is demonstrated. Plasma biomarkers and mediators such as chemokines, cytokines, adipokines, miRNA reflect the degree of inflammation. Vascular calcification appears to result from induction of osteogenic differentiation in vascular cells by inflammatory factors and other regulators such as RANKL and OPG. Inflammatory proteins and cytokines stimulate OPG expression, particularly in vascular wall cells. OPG inhibits vascular calcification whereas RANKL activation contributes to vascular calcification. Moreover, OPG blocks the actions of RANKL which is found increased in calcified vessels.

OPG/RANKL pathway could be a potential target for therapeutic interventions. Denosumab is a human monoclonal antibody against RANKL, inhibiting osteoclast actions. It mimics the protective OPG action. 


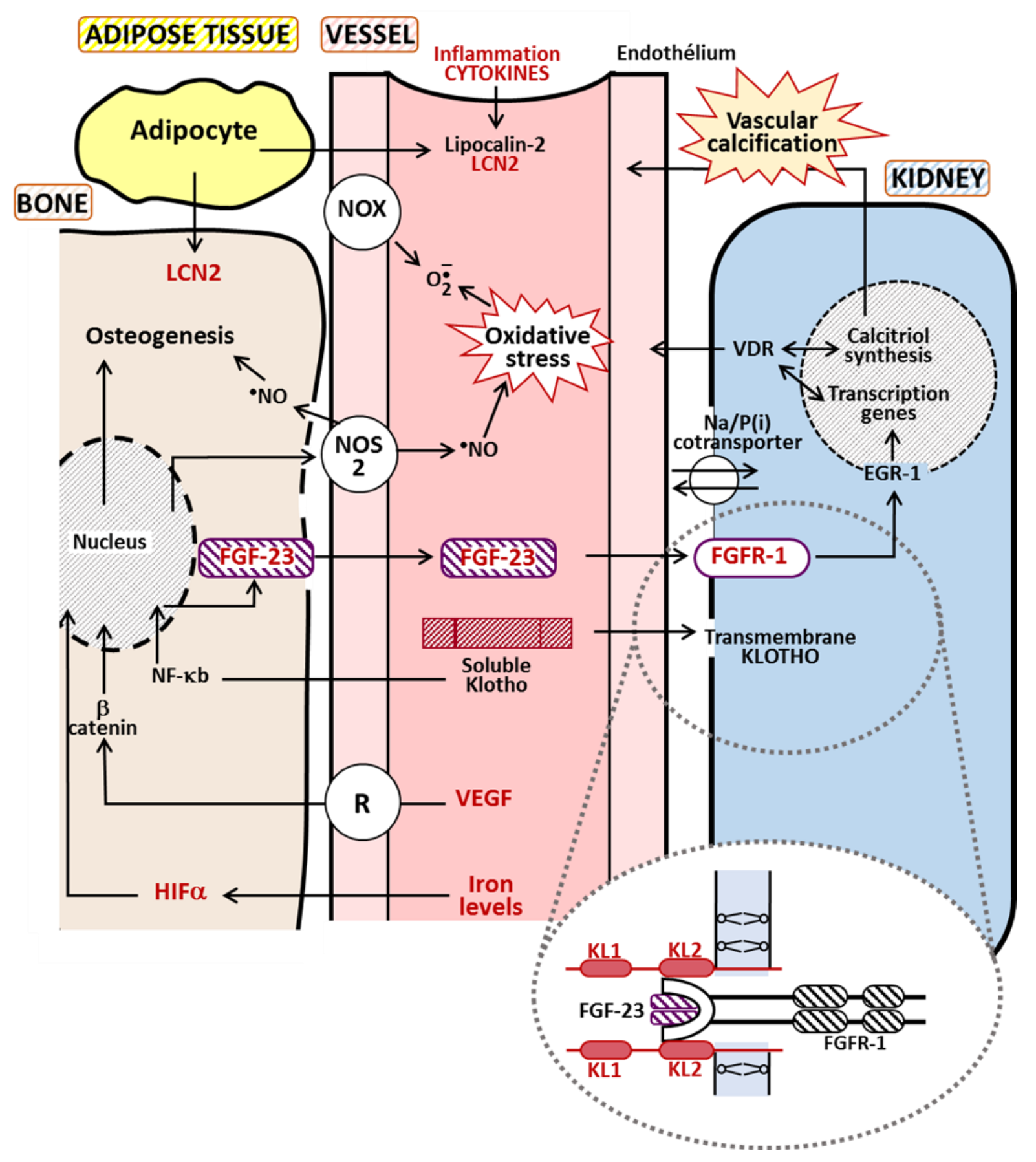

Figure 1 
Inflammatory Lymphocyte Monoocyte

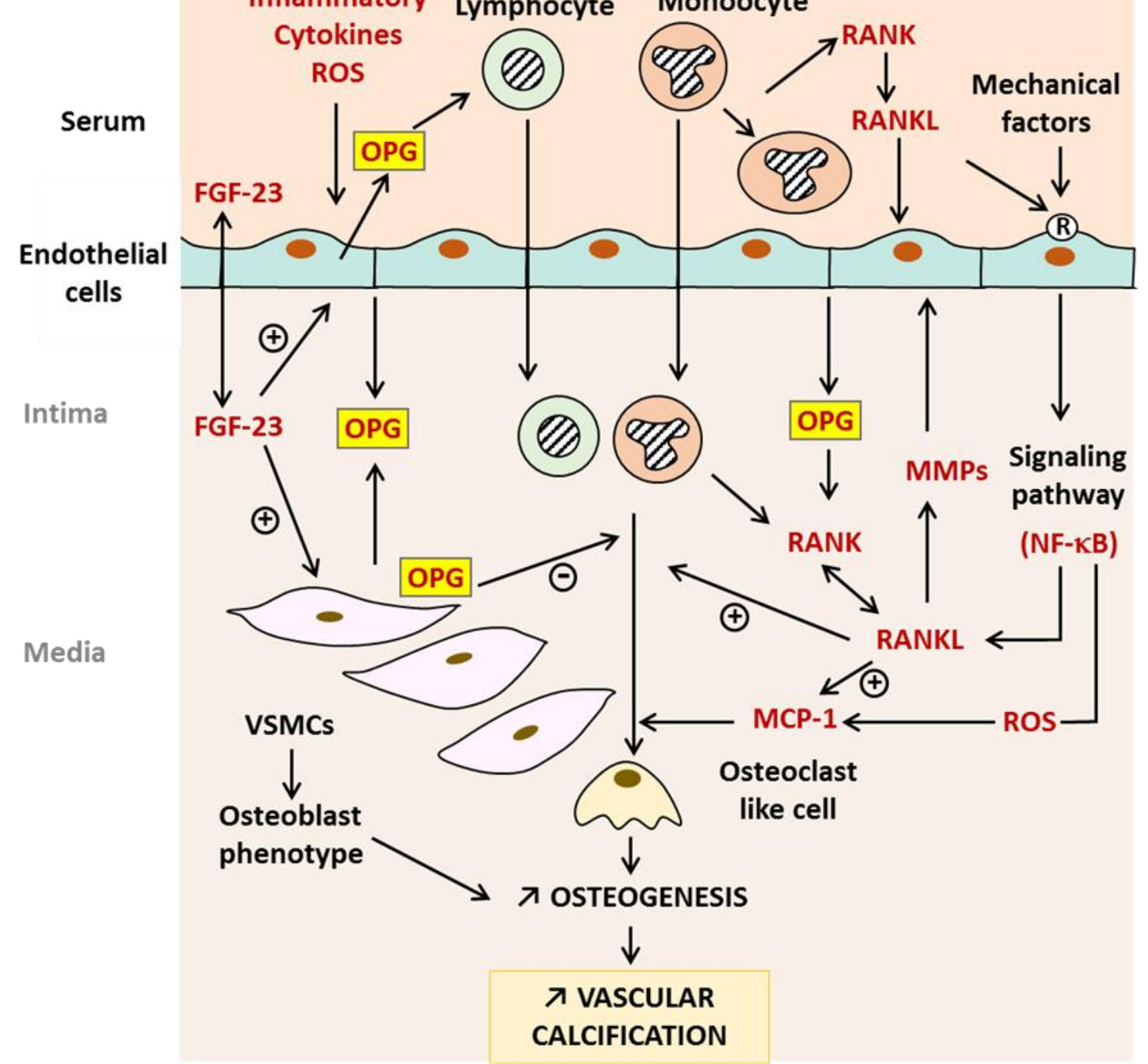

Figure 2 


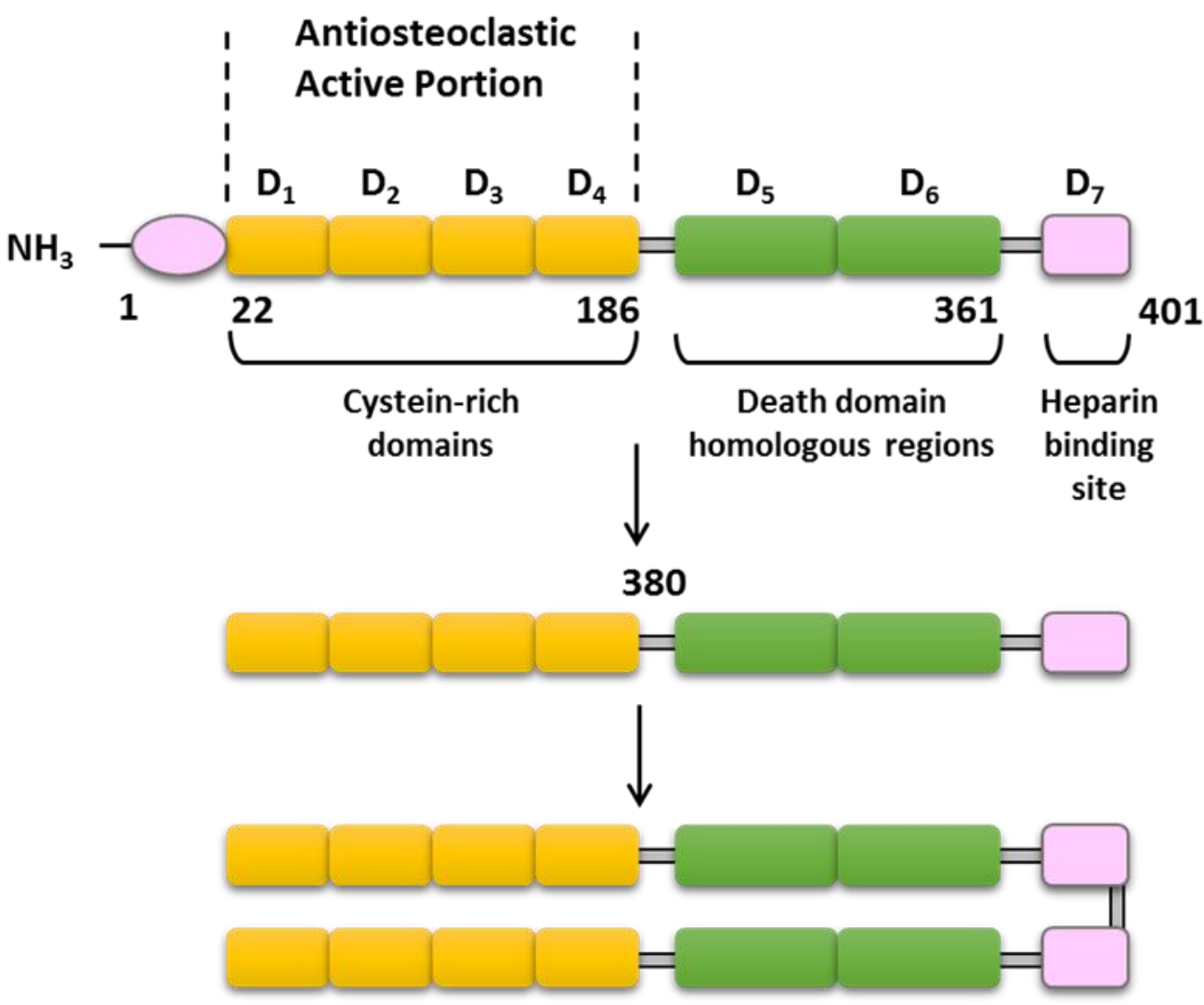

Released OPG dimer

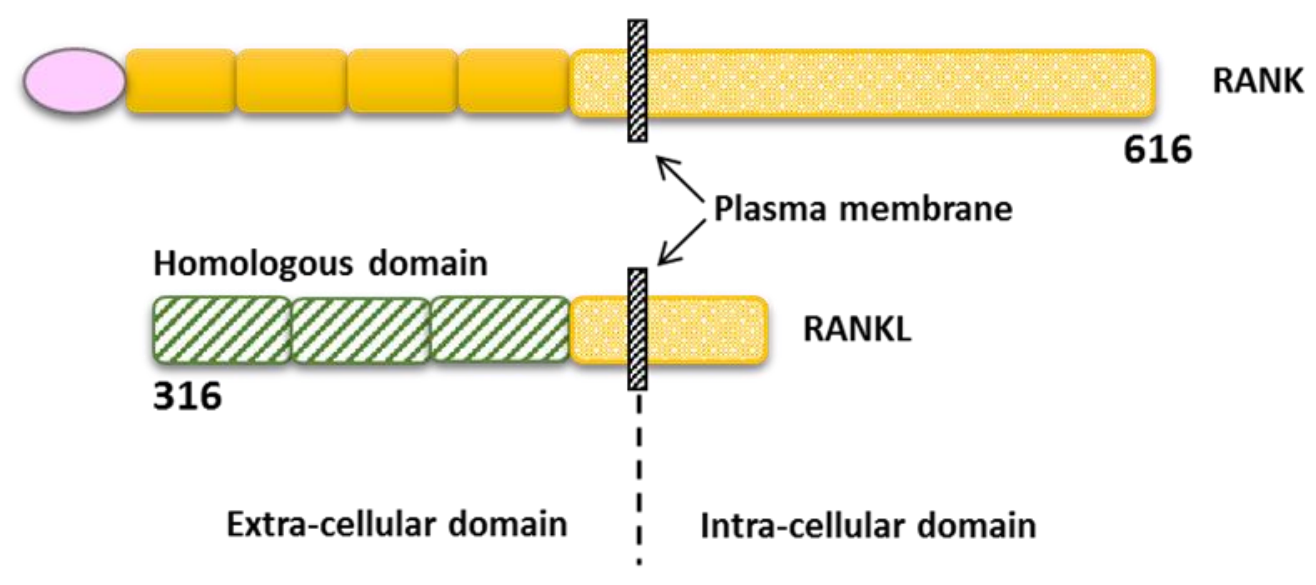

\section{Figure 3}




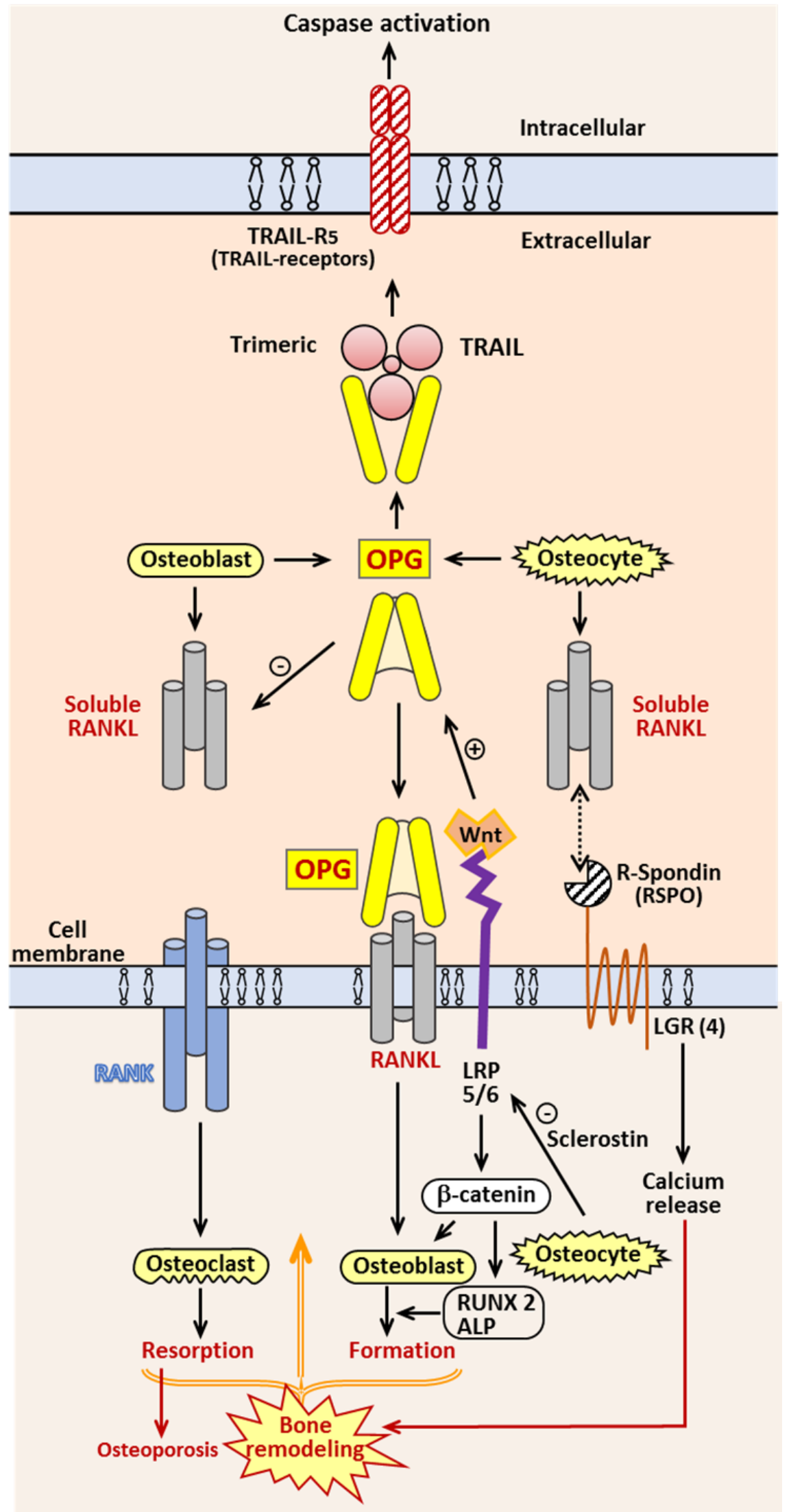

Figure 4 


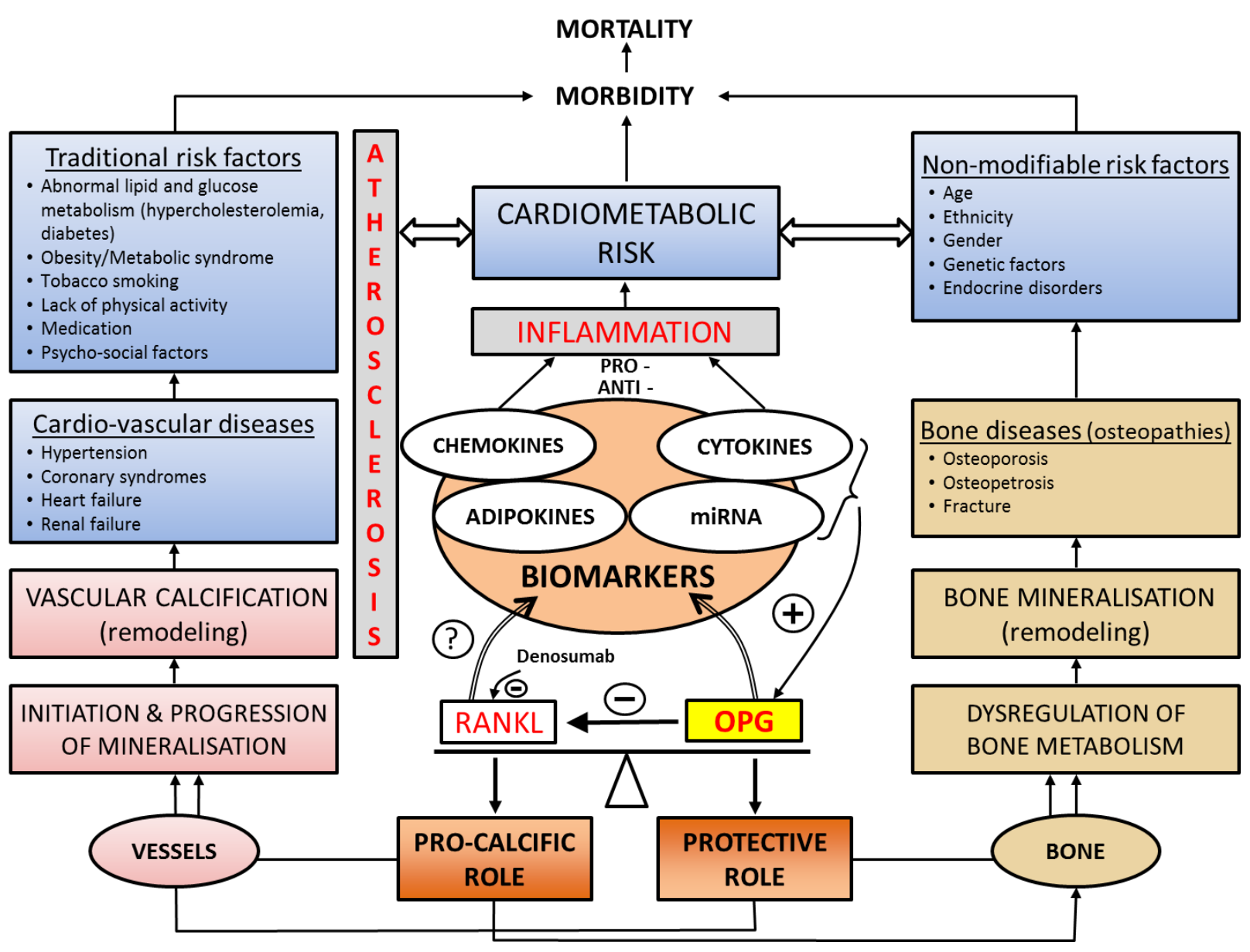

Figure 5 